\title{
CLAUSTROS DE LA FACULTAD DE MEDICINA DE VALENCIA ENTRE 1683 Y 1704
}

\author{
Pascual Marzal Rodríguez \\ UNIVERSITAT DE VALENCIA
}

\section{Origen y fundación de la Universidad de Valencia: una universidad municipal}

Los intentos de fundar un estudio general en la ciudad de Valencia, tras su reconquista por el monarca Jaime I, no fructificaron a pesar de haber conseguido la aprobación papal de Inocencio IV en 1245. Las razones están todavía por aclarar pero la magnitud de la empresa, la situación política del reino recién conquistado y la falta de una demanda estudiantil satisfecha con enseñanzas tradicionales de origen judeo-árabe, impidieron que la iniciativa prosperara. Tendrán que pasar dos siglos para que vuelva a plantearse la necesidad de crear una universidad en la ciudad de Valencia. En este segundo intento ya no será el rey, sino el municipio quien proponga su creación, alegando, como razón fundamental, los desplazamientos que los alumnos valencianos debían realizar a otras universidades foráneas. El municipio, firme en su decisión, aprueba en 1499 las primeras constituciones del estudio general y, un año más tarde, pone en funcionamiento la universidad sin esperar la preceptiva aprobación papal y real. Las bulas de Alejandro VI, el papa Borja, se conceden el 23 de enero de 1501 y la sanción real de Fernando el Católico el 16 de febrero del año siguiente. 
El decidido peso del municipio en su aprobación, los antecedentes de otras universidades catalo-aragonesas con fuerte vinculación municipal, y el financiamiento de sus gastos con rentas municipales - salvo la renta de Orihuela y las pavordías que recaerán sobre ingresos eclesiásticos- motivaron que en la organización y dirección del estudio general valenciano tuvieran una acentuada intervención los poderes locales. Así, la ciudad nombrará al rector cada tres años, designará a los profesores anualmente, etc.

La importancia del municipio en la organización universitaria vino a contrarrestarse, de hecho, cuando el papa Sixto V mediante una bula de 30 de octubre de 1585 concedió a la universidad una parte de las rentas de la catedral de Valencia sobre diezmos en Gandía y Javea -la llamada pavordía de febrero- para crear dieciocho cátedras con dignidad de pavorde. Esta concesión no fue gratuita. A cambio de ella, el papa exigió que el rector fuera nombrado entre algún canónigo de la catedral, además de acentuar la presencia religiosa en el Claustro Mayor, verdadero director de la vida universitaria y órgano a quien correspondía elaborar las constituciones de la universidad. A partir de entonces, este claustro estaría formado por los representantes de la ciudad — jurados, racional, síndico, abogados y escribano- y miembros del estamento eclesiástico - canciller, rector y dos canónigos de la Seo-. El canciller era por derecho propio el arzobispo de Valencia, participaba en la aprobación de las constituciones, así como en la concesión de grados y admisión de graduandos de otras universidades. Por su parte, el rector regulaba, entre otras, las conclusiones que debían celebrarse los sábados, el comedor de estudiantes y, juntamente con los profesores, fijaba las materias y libros que tenían que explicarse durante el curso (1). En esta organización universitaria, los claustros de la facultad de medicina quedaron oscurecidos. Apenas teníamos noticias de su existencia, si bien, ahora comienzan a aparecer sus actas.

\section{La Facultad de Medicina}

Durante el siglo XVI la facultad de medicina se consagró como una de las facultades más sobresalientes de la Universidad de Valencia y de toda la geografía española (2). El protagonismo que adquirió se hizo patente por varias circunstancias. En primer lugar, destaca el elevado número de estudiantes graduados, en contraposición con el resto de facultades que 
integran el estudio general valenciano; muchos de ellos son forasteros, prueba del influjo de su fama. Así, durante 1534 a 1561 frente a los 44 bachilleres de teología, los 8 de leyes, o los 6 de cánones, encontramos graduados 107 bachilleres en medicina. Descompensación que se mantendrá durante el siglo XVII, pues frente a 358 graduados de medicina en el periodo de 1621 a 1634, sólo aparecen 36 en leyes, 131 en cánones y 158 en teología. Los datos de matrícula que se conservan entre 1695 a 1700 muestran igual tendencia (3).

En segundo lugar, la masiva afluencia de estudiantes fue compensada con la dotación de un número mayor de cátedras, ocho en total. Las constituciones de 1611 reglamentaron su número y el contenido de las asignaturas. En el primer curso se leía el libro de Hipócrates De natura hominis y los tratados de Galeno De temperamentis y De facultatibus naturalibus; el catedrático del segundo curso debía explicar el libro De morbo et symptomate de Galeno, mientras que en el tercero los tratados De pulsibus, De urinis y De differentiis febrium, igualmente de Galeno. Al profesor de anatomía se le obligaba explicar la historia de totes les parts de nostre cos, comenzando por los huesos, pasando por las tres cavidades, los músculos, nervios, venas y arterias; las enfermedades sobre estas materias se comentarían por el profesor de prácticas. En la cátedra de hierbas o simples se leía el Methodo universal, y los libros cuarto y quinto De simplicium medicamentorum facultatibus, así como los llamados simples de la botiga; del mismo modo, se obligaba al catedrático a realizar salidas periódicas para que los alumnos vejen y coneguen ocularment los diferentes tipos de hierbas. En la asignatura de Hipócrates se leen los aforismos, los pronósticos y la obra De victus ratione. En la de práctica, se explicaba la causa de las enfermedades, sus indicaciones y curación. Para la cátedra de cirugía se reglamentaba la lectura de materias relativas a heridas y úlceras (4).

En tercer y último lugar, se manifiesta la importancia de la facultad de medicina al tener concedido privilegio para celebrar claustro separado de las demás facultades; punto que va a ser objeto de desarrollo en el epígrafe siguiente.

\section{Claustros de la facultad de medicina de Valencia entre 1683 y 1704}

La Universidad de Valencia desde su creación hasta la época borbónica, se ha caracterizado por la escasez de sus fuentes de estudio. Los mate- 
riales que conocemos se centran en sus estatutos y constituciones, sus libros de matrícula, nombramientos de profesores, determinados aspectos de su financiación etc., que nos proporcionan, con algunas excepciones, una visión universitaria, netamente institucional. Este artículo reúne y presenta una serie de claustros universitarios de la facultad de medicina de Valencia de finales del siglo XVII, los cuales, aunque en una universidad municipal tienen escasa importancia por lo que respecta al juego de poderes universitarios, nos permiten una visión más íntima o cercana de la vida universitaria.

Al estudiar procesos del tribunal de la Gobernación de Valencia, encontré una demanda interpuesta por el Claustro de medicina en la que solicitaba autorización para imponer una derrama a sus miembros, aportando, como documentación, el acta de un claustro celebrado en 1704. Me sorprendió este descubrimiento pues los claustros que se conservaban en el Archivo de la Universidad de Valencia eran más tardíos (5). En la recopilación de las leyes y demás normas del Protomedicato valenciano encontré la justificación a este hallazgo: la facultad de medicina por costumbre inveterada celebraba claustro separado del resto de las facultades que integraban la Universidad (6). Este privilegio se confirmó por sentencia de la Real Audiencia de Valencia de 17 de noviembre de 1677 (7). Con los datos que pude obtener de ambos documentos, busqué otras actas en los protocolos notariales de la ciudad de Valencia, trabajo que, hasta el presente, ha deparado los siguientes resultados:

$1^{\circ}$. La existencia de una serie de claustros generales de la facultad de medicina y otros particulares de sus electos —elets-, que en estas páginas voy a editar.

$2^{\circ}$. La recopilación de varios Claustros generales de catedráticos de la Universidad, que en un futuro publicaré.

$3^{\circ}$. Las actas que resumen los exámenes realizados por las comadronas ante unos examinadores reales o protomédicos, designados por la autoridad municipal, pero fuertemente vinculados con el claustro y el colegio de cirujanos, al ser elegidos entre sus miembros. Estos examinadores reales han sido estudiados para el siglo XVI por M. ${ }^{a}$ L. López Terrada y J. Pardo (8), pero poco sabemos de ellos, de sus atribuciones concretas, y de sus relaciones y dependencia efectiva frente a cada uno de estos poderes -real, foral y gremial o claustral- Los exámenes de parteras son numerosos en el año 1690 (9) y provocan conflictos en dos frentes, aunque en ambos con un claro trasfondo económico: la percepción de los derechos de examen. El primero de estos pleitos se plantea entre la facultad 
de medicina y el colegio de cirujanos, sobre la competencia privativa o compartida de dichos exámenes; el segundo, entre los examinadores de la facultad de medicina y el propio claustro, por las cantidades que aquéllos debían ingresar en sus arcas (VIII).

El contenido de estos claustros médicos que edito no es tan rico como los celebrados en las universidades castellanas durante estas mismas fechas; pero, sin duda, como el investigador iniciado en temas universitarios observará, nos aportan datos de indudable valor: permiten conocer la población médica, los problemas que el ejercicio médico plantea en la Valencia del siglo XVII, las relaciones entre la universidad y la actividad profesional, etc. Dos tipos de claustros he encontrado: unos generales, en los que se reúnen todos los médicos de la ciudad de Valencia, y otros particulares o de elets -elegidos- por aquéllos que, aunque propiamente no se denominan claustros, aprueban sus acuerdos como órgano colegiado. Tanto en unos como en otros, su contenido básico gira alrededor de cuestiones económicas: administraciones de cuentas, obtención de ingresos etc. Intentar una sistematización de los mismos, es ahora mi intención.

El Claustro general de medicina se forma entre los doctores en medicina residentes en la ciudad de Valencia: afermant ésser la machor part dels doctors en medesina habitants en la present Ciutat, según las actas de sus Claustros generales, a excepción de un supuesto concreto. En este último caso, el claustro es celebrado entre los doctores de la ciudad y sus alrededores o particular contribución: tots doctors en Medecina, de la present ciutat y sa contribució particular, dice el documento (IX).

El Claustro simboliza la unión, perdida en la época liberal, entre la universidad y la actividad profesional. Su vinculación con el mundo universitario se muestra, entre otros indicios, por presidir sus deliberaciones el rector (I, II, III, entre otros), o en su caso, el vicerrector (IX, XI, XII); por desarrollarse sus sesiones en la Capella de nostra Señora de la Sapiència de la universidad, por pertenecer a él los profesores universitarios, y por tratar materias que afectan a la vida universitaria: distribución de los ingresos por la obtención de grados (X), por la administración del hort de herves medicinals (XIV) etc.

La relación del Claustro general de medicina con el mundo profesional es aún más patente. Actúa propiamente como colegio profesional, adoptando, en su estructura interna y funcionamiento, el mismo esquema que los gremios de la ciudad: síndico, procurador (10), depositario (III, X), nombramiento de elets (I, IV, IX, XVI, XX), jueces contadores (XVII) etc. El claustro asumiría las funciones que en Castilla adoptó el protomedicato 
mientras que, como advirtió Granjel, en los otros reinos sería ejercido por gremios y cofradías (11). Esta actividad se desdobla en dos campos: uno, externo y otro, interno. En el primero, defiende los derechos de sus miembros, entendidos como cuerpo, frente a cualquier injerencia, v. gr. de médicos extranjeros (VI), o del colegio de cirujanos (VII). Y en este aspecto son de indudable importancia los dos examinadores que anualmente nombraba el Consell de la ciudad entre los miembros del Claustro de medicina, y cuya misión principal era autorizar el ejercicio de médicos foráneos en la ciudad de Valencia (12). En el segundo, su actividad se dirige a reglamentar el ejercicio práctico de la actividad médica, resolviendo los problemas y las necesidades que en un momento concreto puedan surgir. Así, el claustro de 5 septiembre de 1683 (II) prohibía que los médicos constituyeran igualas con germandats, confraries, officis, vicinitats, gremis y congregacions, hecho que García Martínez denominó un intento de seguro médico (13). Las razones que daba el Claustro para prohibir que los médicos se conduixquen, como así llaman esta práctica, serían, a grandes rasgos, las siguientes: el elevado número de personas que formaban las congregaciones y que debían ser atendidas por un único médico, lo que provocaba una asistencia deficiente e impedía que estos médicos, habitualmente los más inexpertos, carecieran de tiempo para profundizar en el estudio de las enfermedades; en segundo lugar, las igualas dejarían a la mayoría de médicos sin trabajo al cabo de pocos años porque la totalidad de la población valenciana pertenecería a ellas. Por otra parte, en el claustro de 3 de agosto de 1693 (XI, XII) se discutía la posibilidad de que los doctores, no catedráticos, tuvieran médicos en prácticas, y de que estos practicantes fueran admitidos a los grados de bachiller y doctor de la facultad de medicina de Valencia, cobrando sus maestros por ello, las propinas que les correspondieran. Esta propuesta atentaba contra el monopolio que en este campo ejercían los catedráticos de la facultad, y que pronto se reflejaría en el voto particular y protesta que este colectivo haría en ambos claustros. A todas estas funciones Ortí añadiría las de castigar a quien contraviniera los estatutos o aprobar los medicamentos que se introducían en la ciudad.

El Claustro general necesita ingresos para cumplir todas estas atribuciones, en especial los frecuentes procesos entablados en la Real Audiencia -v. gr., contra el doctor Agustí Abaas sobre si éste por ser extranjero podía concurrir al cargo de examinador real de la facultad de medicina (III, VI); o contra la ciudad de Valencia sobre insaculación(III). Las tres principales fuentes de su financiación corren a cargo de: derramas, letras de cambio o cambis y participación en las propinas por obtención de grados. 
1. Las derramas o tachas suponen el reparto de un gasto, calculado previamente, entre tots los particulars de dit Illustre Claustro, que al present vihuen y habiten en la present Ciutat (V), autorizada por el Tribunal del general Gobernador (14). La cuota que se impone no es igualitaria, sino proporcional, dividiéndose en tres escalones impositivos o mans, bien de seis, cuatro y dos libras (V), bien de tres, dos y una libra (XXI). Esta fuente de ingresos tiene interés porque permite conocer la población médica existente en la ciudad -55 doctores en 1690 y 45 en 1704- y, en su caso, su situación económica.

2. ${ }^{\circ}$ La letra de cambio es otro medio al que acude el Claustro de medicina cuando no hia efectes promptes alguns per a poder subministrar los gastos que se oferiran (XIV), siendo las cantidades prestadas variables según las necesidades - 50 libras (XIV) y 100 libras (III)—.

3. ${ }^{\circ}$ Por último, las propinas por la obtención de grados revierten en el Claustro general de medicina por dos caminos. El primero por medio de la participación en las cantidades que por este concepto reciben los catedráticos - cuatro reales, de los cuales dos eran para el Claustro-, así como las entregadas a los graduados que acuden a la lectura de las conclusiones - los cuales reciben dos reales, reservándose el Claustro, uno- (X). El segundo, directamente en las propinas que entregan los graduandos y doctorandos, esto es, que els que de huy en avant es graduaran de bachiller, hachen de pagar una lliura de tacha cascú y altra lliura cascú que es graduarà de doctor (X) (15). Cantidades ambas que pasan a ser depositadas en manos del Prior del Claustro.

La administración de sus cuentas se encarga al depositario, nombrado en algunas ocasiones por el Claustro general (III) y en otras por el claustre de elets (X), el cual al finalizar su cargo presenta la contabilidad estructurada en dos apartados, uno de ingresos y otro de gastos, o lo que es lo mismo, de cargos - càrrechs- y descargos - descàrrechs- (XIII, XV, XIX). La inspección de la misma corresponde a los jueces contadores nombrados, a su vez, por el Claustro general (XVII).

Además de ingresos, el Claustro general de medicina necesita unos órganos ejecutivos que pongan en práctica sus acuerdos, son los llamados electos -elets-. Designados por aquél mediante mayoría simple (puede verse en todos los claustros, pero en especial XVII y XVIII), lo representan, y en su nombre, ejecutan sus acuerdos. Los elets pueden ser designados para formar un órgano colegiado (I, IV, IX, XX), o bien con carácter particular para ejecutar determinadas decisiones, como por ejemplo la elaboración de unas nuevas constituciones (XV); todo 
dependerá del poder que en el acto de su nombramiento, o en una adición posterior, se les conceda. Las cláusulas de concesión son muy minuciosas (I).

Los electos que forman el órgano colegiado varían entre siete (IX, XX) y nueve miembros (I). La indeterminación de su número, no sé exactamente a que responde, quizá la explicación se encuentre en si se computan o no, los elets designados para funciones concretas. Si bien, Ortí y Figuerola señala que eran nueve, graduados todos en la misma Facultad y algunos de ellos catedráticos.

\section{La abolición de fueros y el claustro de medicina}

El decreto de 29 de junio de 1707 dictado meses después de la batalla de Almansa, abolía los fueros y privilegios que habían gozado los valencianos durante casi quinientos años; sometiendo el Reino de Valencia a las leyes de Castilla. Sus consecuencias para el claustro de medicina fueron decisivas, pero no tanto para sus prerrogativas dentro de la organización universitaria, que eran escasas y parece que quedaron inalteradas. Prueba de ello es el importante memorial que el Claustro de medicina presentó en 1721 a la ciudad de Valencia para la renovación de los estudios médicos universitarios, y que se plasmaría en el capítulo XII, apartado 8 de las Constituciones de 1733 (16). Norma que rompía la rigidez de los textos que debían explicarse en las aulas, y permitía introducir los nuevos avances que se habían producido en el campo de la medicina.

Sin embargo, el efectivo control del ejercicio médico por el Claustro de medicina sí que quedó gravemente modificado. La Nueva Planta, al menos teóricamente, había dejado al Claustro de medicina sin una base normativa. Sus privilegios quedaron derogados junto al resto del sistema normativo foral y en este momento debió replantearse sus competencias frente a un órgano castellano extraño para los médicos valencianos como era el protomedicato, cuya implantación en el Reino de Valencia no sería automática. Durante los años posteriores a la abolición parece que el claustro de medicina continuó celebrando juntas, como constatan algunas anotaciones existentes en el libro de priorato de medicina (17), pero desconozco su contenido, ni si las funciones del claustro respondían a las que había desempeñado en época foral, pues no he logrado localizarlos por el momento. A pesar de ello, las competencias del claustro de medicina como órgano 
de control del ejercicio médico desaparecerán efectivamente hacia 1736. Esta fecha marca un largo proceso de altibajos en el que el Claustro de medicina intentó volver a la situación existente antes de la abolición. Parece que una de las primeras actuaciones del claustro médico fue recordar mediante un memorial de 27 de julio de 1716 al cabildo municipal, las competencias que en el nombramiento de examinadores reales había ejercido la ciudad «desde los principios de la centuria de 1400 hasta el año después del de las turbaciones deste Reyno". Ante este memorial, la ciudad solicitaba informe a sus abogados, visto el cual se aprobaba el regreso al sistema foral, y así, se disponía que los examinadores de médicos y cirujanos se eligieran «el día veinte y dos de deziembre del año próximo venidero de mil setezientos y diez y siete en adelante, por guardar y observar el método y posesión antiquada»; mientras que para los cuatros meses que quedan para finalizar el año, pues esta resolución se aprueba en agosto, son elegidos como examinadores médicos los doctores Tomás Longás y Matías Morales (18). La normativa foral no sé exactamente cuanto tiempo se mantuvo en vigor, pues en el año 1735 el claustro de medicina presentaba al Rey una provisión en la que solicitaba el reconocimiento de sus antiguos privilegios (19), en especial, los concedidos por Felipe IV en las cortes de 1626, relativos a la prohibición de ejercer la medicina en el Reino de Valencia a persona que no fuera graduada en la Universidad de Valencia, salvo los que se aprobaran como hábiles por los examinadores de la facultad de medicina (20); privilegio que durante los siglos XVII y XVIII será fruto de continuos enfrentamientos con la Universidad de Gandía (21). Como se ve, el Claustro de medicina pretendía conservar el control y monopolio sobre la clase médica del Reino de Valencia que las nuevas leyes habían puesto en entredicho, y evitar, de este modo, todo intrusismo foráneo.

Ante tal demanda, el rey pide a la Audiencia de Valencia que le informe. No he encontrado contestación expresa al Claustro de medicina pero, al año siguiente, el monarca implanta de forma efectiva el protomedicato castellano en el Reino de Valencia. Mediante una carta orden de 7 de noviembre de 1736 dirigida a los cirujanos, médicos y boticarios se establecían las líneas generales de su actuación:

$1 .^{\circ}$ Se distinguía si el médico quería ejercer dentro o fuera de la ciudad de Valencia. En el primer caso, después de haber cursado sus estudios, "deven acudir precisamente al protomedicato de esta corte para pedir y sacar comisión a efecto de examinarse por los oficiales y examinadores de el Colegio a los cuales necesariamente se ha de cometer, y estando ejecutados por ellos los exámenes y aprobación de el pretendiente, recurrirá y 
volverá éste al protomedicato por el título que se despachará en la forma acostumbrada sin más gasto ni costa que a los demás y con la expresión de que es para ser colegiado de la ciudad de Valencia». Para los que quisieran ejercer en las demás poblaciones del Reino se ordenaba que se practique lo que «antes de la abolición de los fueros y privilegios de la Corona de Aragón se ejecutava, en los reinos en que había protomédicos».

2. ${ }^{\circ}$ Debían remitir sus ordenanzas al Consejo de Castilla «a fin de examinar y aprobar las que fuesen útiles a su gobierno y corregir las excesivas en punto de derechos de caja y de examinadores, regulándolos a lo justo con consideración del gasto que los colegiados han de tener en el protomedicato por medio de la presente providencia».

3. ${ }^{\circ}$ La disposición más importante suprimía las prerrogativas del claustro en la resolución de quejas y recursos de los aspirantes, pues «en lo directivo y gubernativo han de quedar el colegio y sus individuos enteramente sujetos y subordinados al Real protomedicato desta Corte».

4. ${ }^{\circ}$ En último lugar, disponía que como "en el Reino de Valencia no hay protomédico particular, vengo en que el protomedicato de esta Corte dispute y envíe de dos en dos años un profesor para la visita de títulos, tiendas y boticas, y reforma de excesos que pudieran introducir, y es de su obligación cautelar como la ejecuten los demás protomédicos en los Reinos donde los hay particulares» (22).

Las protestas parece que no se hicieron esperar pues al mes siguiente se dictaba otra carta orden encabezada con estas expresivas palabras: «Fatigada la Real atención del Rey con los impertinentes, continuados recursos de los médicos, cirujanos y boticarios de ese Reyno a fin de vivir independientes y sin la debida subordinación a este Real protomedicato", pasaba a reiterar la superioridad del protomedicato castellano, la prohibición de no admitirse más recursos y la amenaza de un severo castigo para aquél que no cumpliera las disposiciones hasta entonces aprobadas (23).

\section{I}

Claustro general de medicina en donde se nombran sus electos

Die XIII mensis Junii anno a nativitate Domini MDCLXXXIII (13.6.1683)

Anno a nativitate domini millessimo sexcentessimo octogessimo tertio. Die vero intitulato decimo tertio, mensis junii. Joan Batiste Bonet, Gaspar Regal, Joseph Viñau, Sal- 
vador Moliner, Bertomeu Selma, Joan Batiste Gil, Vicent Estruch, Fransisco Vidal, Fransisco Leonart, Joan Batiste Caudí, Macia Domingo, Agustín Abas, Jaume Boix, Juseph Canti, Joan Batiste Gisbert, Joan Batiste Ferris, Esteve Falcó, Francisco Durbà, Gaudencio Senach, Juseph Navarro, Roch Soler, Gaspar Galindo, Joseph Rebull, Francisco Estelles, Tomas Micó, Vicent Guillen, Grabiel Tremolet, Felip Alfani, y Juseph Antoni Gil, tots doctors en medecina, en presència y asistència de Fransisco Chabert, prebere, doctor en cànons, canonge de la Seu de la present ciutat y Rector de la Universitat de aquella, ajustats y congregats en la Capella de nostra Señora de la Sapiència de dita Universitat, entre les onse y dotse hores ans mijorn, a hon per a semblants afers y negocis se solen y acostumen juntar y congregar, havent presehit convocació feta per Francisco Beltran, vedel de dita Universitat, lo qual mijansant jurament a nostre Señor Déu Jesuchrist, y als Sants Cuatre Evangelis de aquell en mà y poder del notari infraescrit, prestat, a fet relació ell haver convocat a tots los desús dits y més doctors en medesina habitadors en la present ciutat, per a el present dia, hora y puesto, y essent així tots junts, afermant esser la machor par dels doctors en medesina habitants en la present Ciutat, y com a tals representant lo Il.lustre Claustro de dita facultat de medesina, y tots unànimes y concordes, y ningú discrepant per tenor de la present, en lo millor modo que poden, elegeixen y nomenen en elets de dit Il.lustre Claustro als doctors, Joseph Viñau, Felix Julià Rodriguez, Bertomeu Selma, Joan Batiste Bonet, Joan Batiste Gil, Vicent Estruch, Masià Garcia, Jaume Boix y Gaudencio Senach, tots presents y acceptants menys los dits doctors Felix Julià Rodriguez y Masià Garcia, que estan ausents, donant los poder y facultat a tots junts, eo a la machor part de aquells, per a reformar dit Il.lustre Claustro de medesina en la present Ciutat y sa contribució, tantes quantes vegades voldran y ven vist los serà, y representació que acostuma la machor part de tots los doctors, graduats habitants en València, fent qualsevols del.liberacions y constitucions que els pareguen ser necessaris y convenients, ab los pactes, condicions, penes y demés a d'aquells ben vistes, per a conservasió y onorificiènsia de dita facultat, del mateix modo y forma que tot lo dit Il.lustre Claustro, eo la major part pot y acostuma, de tal manera, com si per tot lo dit Il.lustre Claustro fosen fetes, donant-los poder y facultat, així mateix a tots los dits elets, per a que aquells, eo la machor part de aquells puxen buscar y pendre, qualsevols cantitats de diner que sien necessàries y que a d'aquells eo, a la machor part parega, y ben vist sia en una o mès vegades per a qualsevols effectes, tant a cambi, com en qualsevol altra forma que el podran trobar, fermant los actes necessaris en poder de qualsevols notari, o notaris, ab totes les clàusules executives y guarentígies, ab executoria, comensant per pacte a peñores, com a deutes fiscals y reals, ab jurament de no possar rahons summissió y renunsiasió de fur, variasió de juhí, obligació de bèns y demés clàusules oportunes y necessàries y en semblants actes possar acostumades, segons lo estil y pràctica del notari, o notaris rebedors y ab les renunsiasions dels benifets del cedir y dividir les accions epístola del divo Adrià, fur de València y qualsevol altre que sia necessari y que és trobe introduhit en favor de dit Il.lustre Claustro, y si fos necessari y paregués a d'aquells, per a que puguen escriure a Sa Magestat les cosses que ben vistes los seran, donant-los tot lo poder y facultat necessari per a poder fer axí tot lo desús dit com lo demés que tot lo dit Claustro junt fer podria, donant-los y atribuhint-los tot lo poder necessari a dits elets, eo, a la major part de aquells, y tal qual lo te dit Il.lustre Claustro per a desidir, determinar y possar en execusió totes les cosses que ben vistes los seran adaquells, eo a la machor part y machor lluhiment de dita facultat, ab la clàusula general y ab incidents y dependents 
annexos, y connexos. Tot lo qual fan y entenen fer, com a representants dit Il.lustre Claustro y en lo millor modo que poden y de justícia els es llícit y permés, loant y aprobant nunc protunc totes les dites cosses y cascuna de aquelles, per a la machor validitat desde la primera linea fins a la última inclusivament. De totes les quals cosses requeriren a mi Victor de Salafranca notari públich de la present Ciutat y regne de València, los rebes acte públich, per a haverne memòria en lo esdevenidor, lo qual per mi, dit notari los fonch rebut en los lloch, dia, mes, any, e hora desús dits. Essent presents per testimonis a dites cosses Andreu Martinez; estudiant, y Jasinto Sanchis, alguasil de dita Universitat, habitadors de València.

Archivo del Corpus Christi. Notario Víctor de Salafranca. Protocolo 14967.

II

\section{Claustro general de medicina en el que se prohibe que los médicos constituyan} igualas con gremios, cofradías etc.

Die quinto septembris anno a nativitate domini MDCLXXXIII (5.9.1683).

Sia a tots cosa manifesta que nos Isidro Costa, Christofol Pons Trizaña, Joan Joseph Viñau, Feliu Rodriguez, Joseph Roldan, Berthomeu Selma, Joan Batiste Gil, Miquel Noguera, Mathias Garcia, Francisco Leonart, Joseph Cantí, Joan Batiste Caudí, Joan Bahste Ferris, Joan Batiste Gisbert, Augustí Abaas, Francisco Martí, Gaudencio Sanach, Jaume Boix, Esteve Falcó, Joseph Navarro, Martí Xalo, Gaspar Galindo, Francisco Durbà, Antoni Usón, Gabriel Tremolet, Francisco Estellés, Joan Albert, Reymundo Rovira, Macià Domingo, Joseph Antoni Gil y Vicent Struch, tots doctors, metges graduats en esta insigne Universitat de València, commorants en la present ciutat, congregats en la capella de la sacratíssima verge Maria, sub titulo de la Sapiència, dins lo estudi general, hon (segons la Real sentència publicada per Joseph Lorens de Saboya, cavaller escriba de manament, en el deset de nohembre mil Siscents setanta y set, sots audició del magnífich Isidor Aparici Gilert, doctor de la Real Audiència, en lo proces ab inmició del syndich de tot lo Claustro de dita universitat, del procurador patrimonial de Sa Magestat, y del subsyndich de la present ciutat tenim possessió de juntar lo Claustro de nostra facultad), convocats per Francisco Bertran, bedell de dita universitat (qui ab jurament en poder del notari infrascrit, presta a Déu nostre Señor, y als quatre sancts Evagenlis, davant los testimonis infraescrits, refer, de manament del infrascrit señor Rector haver convocat per a aquest loch y hora, y del.liberar coses concernents al govern de dita facultat y Claustro, a tots los doctors, metges de la present ciutat) essent la major part de tots los dits doctors, en presència y asistència del molt reverent señor Francisco de Chabert, doctor en cascun dret, canonge de la Metropolitana església de València, meritíssim Rector de esta insigne Universitat. 
Per quant novíssimament se ha advertit un abús introduhyt poch ha en la present ciutat, arravals y sa contribució particular, de molt perniciosa conseqüència a dit Claustro, havent-se applicat y reduhyt alguns doctors a un exercici indecorós a la medicina, no advertint que si bé està generalment en totes les nacions per lo benefici de la pública salud és estimada y ben acceptà, meritament $\mathrm{y}$ ab especialitat se ha usurpat la major y primera estimació aquest Claustro de València, y a per los florits ingenis que ha produhyt y produheix, com ho testifiquen ses obres, y a per altres títols que la modèstia no ens permet referir, y que per ço no poden los actuals doctors no aa erir als vestigis dels antecessors que la constituyren en honestíssima occupació, puix ab semblant reduhyda y abús, la han reduhyda a inútil y despreciable tarea en esta forma:

Viuen de les dotse parts dels vehyns de València y sos arravals, casi les diuen Germandats, confraries, officis, vicinitats y altres diferents gremis y congregacions, cascuna és de docents o trecents y mes pares de familia, o cases y assigna per a un doctor, metge salari annuo, que el maior és de vint o vintycinch riures, ab obligació de visitar totes les dites cases y families. Soliciten y negocien alguns de dits doctors semblant conducció, no zelada y vergoñosament (com dihuem y encara repudiar-la), pero ab submissions y medis indignes, ab los quals eleven a dits congregats a que és acten de tenir tanta facultat obligada a sa asistència, ab tan incompetent $y$ vil estipendi, motiu que fa detestàble semblant negociació y conducció y poderós, per a procurar sa estincció; quant-no la recomanassen los grans danys que occasiona als mateixos gremis y doctors, així conduhyts y al residuo Claustro, no sent los menors: que els doctors que així se assalarien o conduheixen, havent de acudir a tan gran número de malaIts, no poden visitar-los a tots cascun dia, y de pasarsen així dos y tres, es segueix que o moren, quedant lo escrúpol del defecte de asistència, o es fan incurables, o de pitjor condició les enfermetats, pues los particular y congregats, acostumats, ya a no pagar la visita no busquen altre metge, creent sempre prompte, y esperant al conduhyt. Que sent, com són, los metges així conduhyts ab dites germandat, officis y demés gremis, correntment principiants (per ser en estos més poderós lo desig de acreditar-se) necessiten de tenir moltes hores del dia desocupades per a el estudi, y comprehensió theòrica, pero embarasats y summament occupats en les visites no tenen temps (segons sa pròpia confessió) per a estudiar. Y de assi prove que si consumixen com és precis, algun temps en los libres, queden sens la asistència els malats, y si acudixen a estos y ometent lo estudi, han de curar inmadura y perillosament, pues lo metge a qui falta la literatura y continuo estudi, és precis ser tengut per no segur. Que estànt casi tota la ciutat y sa contribució reduhyda a dites congregacions, sols venen a tenir les visites entre huyt o nou, o pochs mes doctors, de hon se segueix que falta als demés lo necessari empleo, y es podria seguir (si no es provehys ae condecent propte y opportú remey) que dins deu anys no tingués València metge algú de crèdit, pues precissament se'n haurien de anar a hon se occupassen y tinguessen la còngrua y decent sustentació; y seria prejudicial y malvista cosa, que la referida ciutat quedàs entonces ab los metges dels gremis que pateixen la obiecció referida, quant està acostumada a tenirse de tanta suposisio y graduació. Que del salari de vintycinch liures que és lo major que acostumen assignar les germandats, cap poch més o menys al any un real a cascuna casa, y és gran vilipendi que tan gran desvel y estudi conseguir la facultad no tinga respectiu fruyt, merced y remuneració. $\mathrm{Y}$ a més de estos danys e inconvenients de dites conduccions occurixen altres de igual ponderació y moment, que és més decent dexar-los a la 
tàcita consideració. Tots los quals han commogut y commohuen nostre ànimo al remey prompte de que necessita semblant abús, lo qual se atallarà . (a nostra intelligència) mijansant, la observació de esta carta, per tenor de la qual consultament, y ab madur accort, en nom, veu y representació de tot lo dit Claustro de medecina de València, ningú discrepant, per nós, y els futuros professors de aquella perpètuament del.liberam, statuym y ordenem.

Primerament que de huy mes no puixa doctor, metge algú de la present ciutat y sa contribució particular, conduhir-se o asalariar-se per a visitar germandats, confraries, congregacions, vicinitats, officis, ni altres gremis formats fins huy y en avant erigidors en la present ciutat y sa contribució particular, de persones laiques que vihuen en cases privades, per salari algú, y que les conduccions, així fins huy fetes, en lo dia Nadal primer vinent, queden irrites, nulles y suppreses. Ni puixa visitar semblants congregacions, cobrant simuladament lo salari per porcions, com si se li pagassen les visites, ni graciosament, ni ab altra títol, via o manera, cogitada o incogitada, directa o indirectament, ni puixa fer cedules o declaracions dels dies de la enfermetat dels agermanats, excepto sols que puixa visitar los pobres de les paroquies per lo salari que lo Pare de aquells acostuma donar. Y en lo demés, visiten los metges desde huy (com ans de semblant abús satisfets de cascuna visita en les cases a hon seran cridats o asalariats en elles) segons baix se dirà.

Item que ningun doctor, metge desde huy puixa conduhyr-se per a visitar cases, així de la present ciutat, sos arravals y lochs de dos legües en contorn, com alqueries barraques y altres habitacions, per meny salari que de cinh liures annues per cascuna casa, alqueria, barraca o habitació. Y ab los lochs de dos legues alrededor de València no es puixa conduhyr o asalariar-se metge algú, sinó ab.consentiment dels elets del Claustro, a discrecio dels quals pendra congruo y decent salari. Y les conduccions fins huy fetes no conforme en lo desús dit, queden respecte de les cases, alqueries y demés particulars habitacions en lo dia de Nadal primer vinent, irrites y nulles, y en respecto dels lochs comense la observació de aquest capítol acabades les conduccions actuals.

Item que si algun doctor, metge desde huy en avant declarada o simulada, directa o indirectament, y en qualsevol forma contravindrà als dits dos capítols, y lo altre de ells, en tot, o en qualsevol part, ipso facto, sia incurs y multat per la primera vegada en cinquanta liures, moneda reals de València, per la segona en cent liures, per la tercera en dos-centes liures, y si es reincidirà, puixa gravar-lo el Claustro a son arbitre, etiam en privació del ingrés, y veu activa y pasiva en aquell, en suspensió de visitar, y en altres més graves penes a tota disposició del Claustro, rahó manente pacto. Y la pena en tot cas sia exigida per los elets de dit Claustro, o per son syndich, y sia per ella despachada exequció per qualsevol jutje, comensant a peñores, segons se acostuma en la exequció dels deutes reals y fiscals, remot tot privilegi y embaràs, de missió y minoració de la qual pena sols puxa fer nemine discrepante, lo Claustro ple congregat a expenses del qual la demanara; y no sia necessari per a que quede plenament rebut lo incurs altre extrem, que sens citar al reo portar al jutje que ha de ser executor, dos testimonis ad aurem, y si per semblant verbal deposisió pareixerà al jutge, haver contravensió, sia encontinent, despachada la execucló, y sia exigida la pena sens esperar altra solemnitat,o circunstància, ans bé, com si el reo estiguera convençut per pròpia judicial y solemne confessió, rato semper pacto manente. De les quals penes, la mitat sia donada al-acusador y la altra mitat applicada al Claustro y deposada en lo erari per a gastos y obs de aquell. 
IIII. Y últimament per a deixar més estables y exequtives les coses damunt dites que en continent que cascun metge sia admés a lo Claustro haja de jurar per instrument públich així la observació de aquests capítols sots les penes damunt dites, com als eletes o syndich de dit Claustro de qualsevol contravenció commessa per qualsevol claustral, en continent que tinga la notícia sens excepció de persona, sots Pena de perjur. Y en força de aquest capítol tos ex nunc en poder del notari infraescrit jurarem a Déu nostre Señor, y als sants quatre Evangelis, observar les coses damunt dites, sots les penes de perjur y demés apposades, y donar avís en continent que el tingam, de qualsevol incurs y contravenció a dits capítols sots la mateixa pena de perjur.

De totes les quals coses per a futura memòria requirim ésser rebuda pública carta per lo notari infrascrit, yo Joan Symian per Authoritat Apostòlica y de València, notari apostolich, lo rebí en dita Capella de nostra señora de la Sapiènsia, dins lo estudi general de València, en lo dia cinch de setembre, any de la nativitat de nostre señor Déu Jesuchrist, mil sis-cents huytanta y tres, pulsata hora matutina undecima. Essent a tot presents testimonis Iacyntho Sanchiz, alguacil de la Universitat, Andreu Castelló, estudiant, vehins de València.

Archivo del Corpus Christi. Notario Joan Simiam. Protocolo 1910.

III

Claustro general de medicina en el que se otorga a sus electos poder para imponer tachas o derramas entre los médicos de la ciudad, y se nombran los depositarios de estas cantidades.

Dictis die et anno (10.6.1688)

Anno a nativitate Domini millesimo sexcentesimo octogesimo octavo, die vero intitulato decimo, mensis junii. Juan Joseph Viñau, Felix Rodriguez, Juan Batiste Gil de Castelldases, Berthomeu Selma, Vicent Estruch, Francisco Vidal, Basilio Delfí, Joan Batiste Caudí, Mathias Domingo, Esteve Falcó, Francisco Urba, Gaudencio Senach, Miquel Hoguera, Jaume Boix, Miquel Ferrer, Luys Chiva y Palerm, Francisco Estellés, Juseph Nebot, Thomas Micó, Joseph Antoni Gil, Thomas Vicent Ballester, Pere Traver, Antoni Uson, Joan Albert, Francisco Jaume, Gaspar Galindo, Joseph Calbo, y Miquel Lunbier, tots doctors en medecina de la present Ciutat y de esta habitadors, en presència y asistència de don Thomas Ratto, prebere, arcediano de Molvedre, rector de la Universitat de dita y present Ciutat. Ajustats y congregats en la Capella de nostra Señora de la Sapiènsia, construida dins de dita Universitat, ha hon per a semblants afers, y negocis, se solen y acostumen juntar, presedint convocació feta per Phelip Ferrer, subdelegat de vedell de dita Universitat, el qual trobant-se present feu relació al notari infraescrit, michansant jurament a nostre Señor Déu etc. en ma y poder del dit notari prestat, ell aver convocat a tots los doctors en medicina de la present ciutat y del present Claustro per a els presents puesto, dia y ho-

Asclepio-Vol. XLV-1-1993 
ra, aserent y afirnant, medio juramento ad Dominum Deum etc. ser nosatros la machor part de tots los doctors en medicina, que componen lo present Claustro, tots unànimes y concordes y ningú discrepant, sclenter etc. Cum praesenti etc. delliberam y determinam les coses immediatamentes següents.

Primerament del.liberam y determinam que es done poder als elets que el present Claustro té nomenats per a que puguen impossar qualsevols taches a tots los particulars del present Claustro, y a cadascú respective en aquelles cantitats que pareixeran proporcionades per a acudir als gastos així dels pleits que este Claustro porta coatjubat del Procurador Patrimonial de Sa Magestat, per la Real Audiència contra el dotor Agustí Abbas, y del procés de insaculació que porta ab la Il.lustre Ciutat, com de altres qualsevols que es podran offerir y que aquella tacha la puguen impossar ab la calitat que el que se escusara de pagar lo que se li haurà tachat puixa ser eixecutat traent-li una prenda o prendes ab tota eixecució rigurosa, com ab lo present donam poder als dits elets en la forma desús dita per a fer y eixecutar lo damunt dit.

Item del.liberem y determinem que es nomene un depositari del present Claustro en poder del qual hatjen de entrar y entren, així les cent liures que ab acte rebut per lo notari infraescrit en lo dia huy, lo dotor Felix Rodríguez, lo dotor Joan Batiste Gil de Castelldases y el doctor Berthomeu Selma han prés a cambi per a obs del present Claustro, com també totes les cantitats que importarà la tacha que se impossarà als particulars per los dits elets, ab obligació que aquell que serà nomenat tinga obligació de donar conte als dits elets de aquelles cantitats que entraran en son poder per a que sàpien en què les ha convertides, y el Claustro tinga tota satisfacio; com ab lo present nomenen en depositari de dit Claustro al dit dotor Joan Batiste Gil de Castelldases, ab la dita obligació de donar conte als dits elets per a el qual effecte ab lo present donem a estos tot lo poder que serà menester per a lo desús dit. De quibus omnibus etc. Actum Valentiae etc.

Testes sunt Joannes Geyt, infansonus, et Alexus Dardeñau, pediseguus, Valentiae habitatoribus.

Archivo del Corpus Christi. Notario Fulgencio Artich. Protocolo 5073.

\section{IV}

Claustro general de medicina en el que se nombra dos electos por haber fallecido sus predecesores $y$, asimismo, se ratifica el poder que les fue otorgado a los primeros.

Die XIIII mensis augusti anno a nativitate Domini MDCLXXXX. (14.8.1690)

Anno a nativitate Domini millesimo sexcentesimo nonagesimo. Die vero intitulato decimo quarto augusti. Felix Julià Rodrigues, Joseph Vinyau, Joan Batiste Gil, Martí Xalo, Vicent Estruch, Joan Batiste Caudi, Macià Domingo, Francisco Martí, Esteve Falcó, 
Gaudensi Senach, Joseph Nebot, Thomas Ballester, Thomas Guasch, Joseph Calbo, Joseph Antoni Gil, Lluis Nicolau, Gaspar Galindo, Francisco Estelles, Bonaventura Vicent Vinyau, Basilio Corella, Francisco Jaume, Joan Insa, Joan Albert, Philip Carreres, Salvador Perez y Joseph Ferrer, tots doctors en medecina de la present ciutat. En presència y asistència del Il.lustre don Vicent Carros, prevere, doctor en sagrats cànons, canonge de la Seu de la dita y present Ciutat y Rector de la Universitat de aquella. Ajustats y congregats dins la capella de nostra senyora de la Sapiènsia, construida en dita Universitat, poch aprés tocades les dotse hores de mig jorn, hon per a semblants y altres afers y negosis es solen y acostumen juntar y congregar, havent presehit convocasió feta per Philip Ferrer, delegat de Francisco Beltran, vedell de dita Universitat, segons que lo dit Phelip mijansant jurament a nostre senyor Déu Jesuchrist etc. dix y relació feu a mi lo notari infraescrit en presència dels desús escrits testimonis, ell haver convocat a tots los doctors en medecina habitadors en la present Ciutat, per a els presents dia, hora y puesto, ab comminació presissa que ab los que es trobarien presents es farien qualsevols del.liberacions. Y essent així tots junts y congregats, afermant ésser en lo present ajust y congregació, la major part dels doctors en medecina habitadors en la present ciutat, y com a tals representant a lo Il.lustre Claustro de dita facultat de medecina, tots unànimes y concordes y ningú discrepant per tenor del present, en lo millor modo que poden elegeixen y nomenen en elets de dit Il.lustre Claustro per mort y en lloch del doctors Luis Chiva y Palerm, y Jaume Boix, elets que eren juntament ab altres de dit Il.lustre Claustro, als dits doctors Martí Xalo y Gaspar Galindo, presents y acceptants, donant-los y conferint-los tots y aquells mateixos poders que dit Il.lustre Claustro de medecina té donat y atribuits als demés elets de aquell sens llimitació alguna.

Item del.liberen y determinen tots unànimes y concordes y ningú discrepant, confirmant, segons ab lo present confirmen, tots y qualsevols poders y facultats donats y atribuides fins hui per lo dit Il.lustre Claustro de medecina als elets de aquell així ab actes rebuts per Victor de Salafranca, Joan Simian y Fulgenci Artich, notaris, com per altres qualsevols notaris, sots certs chalendaris, y en especial lo poder que tenen dits elets per a imposar derrames y taches als particulars de dit Il.lustre Claustro, per a acudir als gastos $\mathrm{y}$ càrrechs de aquell, $\mathrm{y}$ en quant menester sia tots unànimes $\mathrm{y}$ concordes $\mathrm{y}$ ningú discrepant, delliberen y determinen donar poder, segons que ab lo present lo donen als dits elets, que el present Il.lustre Claustro de medecina té nomenats per a que aquells, eo la major part de aquells, puixen imposar, e imposen qualsevols taches, y derrames a tots los particulars del present Il.lustre Claustro, y cascú respective en aquelles quantitats que els pareixeran, proporsionades, per a acudir, així al quitament dels dos cambis que per a obs de dit Il.lustre Claustro es prengueren per certs particulars de áquell de propietat de cent lliures cascú; com també a la solucció dels interesos de aquells y a la satisfacció de altres gastos y càrrechs precissos a que al present és téngut dit Il.lustre Claustro, y que la dita tacha, eo derrama, la puixen imposar ab calitat de que el que se escuse de pagar lo que se li aurà tachat, puixa ésser y sia executat ab tota execució rigurosa, real y prompte, trahent-li una prenda o prendes equivalents a la quantitat que se li aurà tachat. dequibus etc. quod etc. Actum Valentiae, ubi supra etc. Praesentibus ibidem protestibus. Philippo Amoros, notario, et Vincentio Maçe, artium magistro, Valentiae, vicinis.

Archivo del Corpus Christi. Notario Ignacio Avellaneda. Protocolo 5096.

Asclepio-Vol. XLV-1-1993 
$\mathbf{V}$

Deliberación de los electos de medicina en el que se aprueba y fija la imposición de una derrama entre los médicos de Valencia.

Die XXVI septembris anno a nativitate Domini MDCLXXXX (26.9.1690)

Anno a nativitate Domini millessimo seccentesimo-nonagesimo, die vero intitulato vigesimo sexto, mensis septembris. Felix Julià Rodriguez, Berthomeu Selma, Vicent Estruch, Joan Batiste Caudí, Martí Xalo, Gaspar Galindo y Gaudensi Senach, tots doctors en medecina y elets del Il.lustre Claustro de medecina de la present Ciutat en presència y asistència del Il.lustre Don Vicent Garros, prevere, doctor en sagrats cànons, canonge de la Seu de la dita y present Ciutat, y rector de la Universitat de dita y present Ciutat; ajustats y congregats en la Capella de nostra señora de la Sapiència, construhida en dita Universitat, poch aprés de tocades les dotse hores de mig jorn hon per a semblants y altres afers y negosis de dit Il.lustre Claustro es solen y acostumen juntar y congregar, havent presehit convocació feta per Felip Ferrer, delegat de Francisco Beltran, vedell de dita Universitat, segons que lo dit Felip, trobant-se present, mijansant iurament a nostre señor Déu Jesuchirst etc. dix y relació feu a mi lo notari infraescrit en presència del desús escrits testimonis, ell aver convocat a tots los elets de dit Il.lustre Claustro de medecina per a els present dia, hora y puesto, ab cominació presissa que ab los que es trobarien present es farien qualsevols del.liberacions,y essent així tots junts y congregats, afermant ésser en lo present ajust y congregacio la major part y casi tots los elets de dit Il.lustre Claustro de medecina; tots unànimes y concordes y ningú discrepant, ussant dels poders atribuhits a dits elets per lo dit Il.lustre Claustro ab actes rebuts per diferents notaris sots certs chalandaris y especialment $a b$ acte rebut per lo notari infraescrit en catorse de agost proppassat, del.liberen y determinen que per a effecte de acudir així a la lluisió y quitament dels dos cambis que per a obs de dit Il.lustre Claustro es prengueren per certs particulars de aquell de propietat de cent lliures cascú, com també a la solució dels interessos de aquells y a la satisfacció de altres gastos y càrrechs precissos a que al present és tengut lo dit Il.lustre Claustro, sia imposada, segons que per tenor del present impossen una tacha, eo derrama fins en summa de dos-centes trenta y quatre lliures, moneda reals de València, la qual tacha eo derrama la hajen de pagar y paguen tots los particulars de dit Il.lustre Claustro, que al present vihuen y habiten en la present Ciutat, ço és, cascú de aquells la quantitat que al present se li assigna, y se li impossa, y que per a dit effecte sien fetes tres mans, ço és, primera, segona y tercera, hon se escriguen tots los dits particulars de dit Claustro y els que estaran escrits en la primera mà paguen a rahó de sis lliures cascú, los de la segona, a rahó de quatre lliures cascú, y los de la tercera, a rahó de dos lliures cascú, segons que en virtut del present fan dites mans y annoten en cascuna los particulars de dit Il.lustre Claustro, que se han de comprendre en aquelles respective en la forma que es segueix. 


\begin{tabular}{|c|c|c|}
\hline $\begin{array}{l}\text { Primera mà, a rahó } \\
\text { de sis lliures cascú. }\end{array}$ & s & $\begin{array}{l}\text { Segona má a rahó } \\
\text { de quatre lliúres cascú. }\end{array}$ \\
\hline $\begin{array}{l}\text { Joseph Solsona } \\
\text { Felix Juliá Rodriguez } \\
\text { Joseph Viñau } \\
\text { Berthomeu Selma } \\
\text { Joan Batiste Gil } \\
\text { Vicent Estruch } \\
\text { Salvador Moliner } \\
\text { Macià Garcia } \\
\text { Gaspar Regal } \\
\text { Miquel Hoguera } \\
\text { Basilio Delfí } \\
\text { Gesualdo Catarroja } \\
\text { Joan Batiste Ferriz } \\
\text { Joan Batiste Caudí } \\
\text { Macià Domingo } \\
\text { Agostí Abbas } \\
\text { Martí Xalo } \\
\text { Joseph Navarro } \\
\text { Gaudenci Senach } \\
\text { Vicent Traver } \\
\text { Gaspar Felix Galindo } \\
\text { Francisco Estelles } \\
\text { Felip Altaví. }\end{array}$ & I & $\begin{array}{l}\text { Ysidro Costa } \\
\text { Joseph Pansano } \\
\text { Esteve Falcó } \\
\text { Miquel Lapiz } \\
\text { Francisco Martí } \\
\text { Francisco Durbà } \\
\text { Joseph Galba } \\
\text { Thomas Micó } \\
\text { Antoni Uson } \\
\text { Joan Albert } \\
\text { Joseph Antoni Gil } \\
\text { Francisco Jaume } \\
\text { Joseph Nebot } \\
\text { Thomas Guarch } \\
\text { Felip Carreres } \\
\text { Joan Joseph Lopez. }\end{array}$ \\
\hline . & $\begin{array}{l}\text { Tercera mà, a rahó } \\
\text { de dos lliures cascú. } \\
\text { Joseph Rebull } \\
\text { Thomas Ballester } \\
\text { Bonaventura Vinau } \\
\text { Joan Ynsa } \\
\text { Salvador Perez } \\
\text { Miquel Lumbier } \\
\text { Joan Batiste Lopez } \\
\text { Francisco Perez } \\
\text { Vicent Salvaterra } \\
\text { Basilio Corella } \\
\text { Joan Casanova } \\
\text { Gabriel Mayol } \\
\text { Joseph Cambra } \\
\text { Luis Nicolau } \\
\text { Joseph Ferrer } \\
\text { Ygancio Paches }\end{array}$ & $\mathrm{u}$ \\
\hline
\end{tabular}


et etiam del.liberen tots los dits elets unànimes, y concordes y ningú discrepant, ussant així mateix de dits poders a aquells atribuits per dit Il.lustre Claustro, que dita tacha y derrama, la hajen de pagar y paguen tots los sobre dits en continent sens excepció alguna, y que si algú dels particulars de dit Il.lustre Claustro se escusara de pagar, sia executat ab tota execució rigurosa y propte, trent-li una prenda o prendes, equivalents a la quantitat que ab lo present tindrà tachada e impossada. Dequibus etc. quod etc. Actum Valentiae ubi supra etc. Praesentibus ibidem pro testibus Andrea Matosses et Josepho Vinet, notarius, dicta urbis Valentiae, habitatoribus.

Archivo del Corpus Christi. Notario Ignacio Avellaneda. Protocolo 5096

\section{VI}

Claustro general de medicina en el que se aprueba la renuncia a continuar el proceso seguido contra los inédicos extranjeros con motivo de si éstos podían ejercer el cargo de examinadores reales y demás privilegios del claustro de medicina.

Die XX mensis martii, anno a Virgineo partu MDCLXXXXI (20.3.1691)

Anno a Virgineo partu millesimo sexcentesimo nonagessimo primo, die autem intitulato vigesimo mensis martii. Juan Joseph Viñau, Fellx Julià Rodriguez, Salvador Moliner, Berthomeu Selma, Juan Batiste Gil de Castelldases, Vicent Estruch, Juan Batiste Caudí, Miquele Alapis, Agosti Abas, Esteve Falcó, Francisco Durbà, Marti Xalo, Juan Baiste Ferrís, Gaudencio Senach, Juseph Calbo, Pere Vicent Traver, Gaspar Galindo, Juan Albert, Juan Antoni Gil, Vicent Bonaventura Viñau, Jusep Nebot, Vicent Falcó, Gabriel Mayol, Jusep Ferrer, Francisco Jaume, Felip Carreres, Ignacio Paches, Jusep Martines y Jusep Favado, tots doctors en medicina, habitadors de la present ciutat de València, ajustats y congregats en la Capella de nostra Senora de la Sapiència construida dins de la Universitat de dita y present Ciutat, a hon per a semblanrs afers y negocis se solen y acostumen juntar, en presència y asistència del noble Don Juseph Figuerola, clergue, canonche magistral de la Yglésia Cathedral de la ciutat de Oriola, rector de dita Universitat, precehint convocació feta per Felip Ferrer, subdelegat de vedell de dita Universitat, el qual mijansant jurament a nostre señor Déu Jesuchrist y els seus sants quatre Evangelis, en mà y poder del notari infraescrit prestàt, feu relació haver convocat more solido a tots los doctors en medicina habitants en la present ciutat que componen lo dit puesto, per a els presents puesto, dia y hora. Tots unànimes y concordes y ningú discrepant, aseent y afirmant ser la major part de tots los doctors en medicina de la present Ciutat, component lo dit Claustro, y tot aquell representant scienter etc. Cum pnts. etc. per lo respectes a nos ben vists, renunciam en lo millor modo y forma que de dret podem, al pleyt y causa que lo dit Claustro coadjuvat del procurador patrimonial de Sa Magestat, ha seguit contra el doctor Agostí Abaas, per lo tribunal de la Real Audiència, sots audició del magnifich Francisco Ortin y Luqui, generós, quondam D.D.R.C. y ara segueix sots audició del noble don Matheu Ro- 
drigo, etiam D.D.R.C., en juhí de suplicació, del qual és escriva Feliciano Armendari de Medina, notari. La pretenció del qual consistix sobre si podia lo dit doctor Agostí Abaas, per ser foraster, concurrir al ofici de Examinador Real de dita facultad de medecina, y a totes y qualsevols instâncies per lo dit Claustro, eo sos llegítims síndichs, en aquell fetes a prima linea usque ad ultiman inclusive taliter etc. y així mateix representant lo dit Claustro renunciam a qualsevol acció y pretenció que lo dit Claustro puga tenir y tinga nunc, et in futurum quomdocumque et qualiter cumque, contra qualsevols meches forasters, vasalls de Sa Magestàt, que puga tocar en lo desús dit de si poden o no, concurrir al dit ofici de Examinador Real de dita facultat, imposant-nos en quant menester sia, silenci y callament perdurable. Volent que per a que la present renunciació en tots temps tinga son degut efecte y execució, y tota validitat es decrete per aquell tribunal que sia més convenient y necesari a costes y despeses del present Claustro. De quibus etc. Actum Valentiae etc.

Testes Hyacinthus Sanchis, alguacirius universitatis, et Dionisius Gomis, serici textor Valentiae vicini.

Archivo del Corpus Christi. Notario Fulgencio Artich. Protocolo 5076

\section{VII}

Claustro en el que se adprueba una concordia entre el Claustro de medicina y los examinadores de comadronas.

Die XXIIII septembris anno a Virgineo partu MDCLXXXXI (I (24.9.1691)

Nos Joannus Joseph Viñau, Felix Jualianus Rodriguex, Joannus Falco, Franciscus Durbà, Gaudentius Senach, Gaspar Galindo, PhiLipus Altavi, Petrus Vincentius Traver, Joseph Antonius Gil, Franciscus Jaume, Bonaventura Viñau, Basilius Corella, et Stephanus Alegret, onmis doctores, medici praesentis civitatis convocati et congregati in sacelo virginii 'Maria Sapientis intus Universitatem dicta et praesentis urbis constructo, ubi pro similibus et aliis per agendis negotiis soliti sumus convocari et congregari in praesentia et asistentia don Josephi Figuerola, clerici SSDs., canonici magistralis civitatis Oriolensis. Relata universitatis vicerectoris, praecedente que convocatione facta per Philipum Ferrer eiusdemque universitatis videlli subdelegatum qui relationem tabelioni infraescripto fecit medio iuramento ad Dominum Deum etc. in manu illius praestito et de ordine et per dicti vicerectoris convocare omnes doctores medicos praesentis urbis ad praesentes, diem, locum, et horam cum convocatione precissa quod cum illis qui adsent, quaecumque delliberationes fierent et intra necesaria, omnes unanimes et concordes, nemineque nostrum discrepante totumque claustrum medecinae representantes ex una, et Joannes Baptista Gil de Castelldares et Joannes Baptista Caudi, doctores medici ipsius met urbis vicini ex altera partibus. Attendentes et considerantes dictum Claustrum litigium sequere, contra Joannem Baptistam Gil per Sanctum Inquisitionis tribunal, et versus dictum Joannem Baptistam Caudi per tribunal Regia Valentiae Audientiae, sub exmaine nobilis dominus Mathei Rodrigo, regii senatoris, scriba Felicianus Almendariis de Medina notarius in et 
super duabus praetentionibus; altera scilicet dictos Joannem Baptista Gil, et Joannem Baptistam Caudi, examinatores regios, qui dicta medicinae facultatis fuere in anno transacto milesimo sexcentesimo nonagesimo incurrisse in penam, unumqueque illorum biscentum librarum, pecuniae Valentiae, -propter conventionem factam inter illos. Relatis nominibus et examinatores regios collegii chyrurgorum in et super examen obstetricum, contra id quod dispositu reperiebatur in quondam delliberationis intro per dictum Claustrum firmato, et apud Ignatium Claret quondam notarius. posteaque civem quarto decimo die mensis agusti anni millessimi sexcentesimi sexagesimi secundi condito; alteraque illos in dicto anno relatis nominibus, certas ex dictarum obstetricum examinibus, dicto Claustro pertinentes, propinas apud se retinuisse; quam ob causam in relatis instatiis pretensum fuit pro parte dicti Claustri, eos resp. condemmando, fore et esse in restitutionem dictarum propinarum, et ad solvendum uniusquisque biscentum libras, ratione dicta poena, animadvertentes quod pro parte relati doctoris Joannis Baptista Gil in illius exonerationem deductum fuisse quod licet ille in relata deliberatione firmaset, a tamen illam nomine propio non firmavit, sed tanquam, unis de dicti Claustri corpore, et ideo ad hoc ut remaneret obligatus ad illius observantiam; necese erat, ut dictum Claustrum etiam obligatum remaneret, quodquidem nullatenis erat dicendum eo quia ad distam delliberationem faciendam, non fuit legitime congregatum, nec modo debito de convocatione ad id facta constabat, neque extabat decreto judicis, roborata et etiam relata obstetricum examina modo relato facta fuisse virtute cuiusdam regia provisionis per Josephum Laurentium de Saboya in litem in locum Eusebii de Benavides Regii mandati scribam vigesimo septimo dle mensis junii, anni millesimi secentesimi nogagesimi publicata cum injuntione relati Calustri obtenta, et pro parte dicti doctores Joannis Baptista Caudi ultra omnia supradicta deductum fuit, illum in relata delliberatione non intervenisse; et respectu praetentionis propinarum pro parte duorum deductum fuit, dictum Claustrum nullum habere ius indictis obstreticum examinibus, nec aliquam destinam in illis portionem et consequenter illos nihil de dicto Claustro percepisse, sed tantum propino seu portiones illis uti Regis examinatoribus ditae facultatis pertinentes ulterius considerantes in litibus finem in certum esse, certosque sumptus et expensas, et transactionem quamvis parvam, pinguiori sententia meliorem esse diversasque personas nostrarum arribarum partium benevolentes, pacemque desiderantes intervenisse, ad hoc ut gratia vitandi lites, et sumptus ad quamdam concordiam deveniremus. Ideo scienter etc. cum praesenti etc. Consitemus una pars nostrum alteri et altera alteri invicem et vicisim et nostris quod in et super negotio praedicto devenimus ad concordiam per capitula sequentia.

I. Primerament és estat pactat, avengut y concordat per y entre les dites parts que lo dit claustro haja de renunciar, segons ab lo present capítol renuncia, a dites causes y dret de tornar a suscitar aquelles, imposant-se silenci y callament perdurable, circa praedicta, absolent en quant menester sia, com ab lo present los absolen als dits doctors Juan Batis: te Gil y Juan Batiste Caudí de totes y qualsevos penes que per rahó de dita del.liberació vel aliis hajen encorregut y de qualsevols propines que aquells hajen percebut pertañents a dit Claustro, sent pacte així real com personal ab aquells ab solemne stipulació roborat de ulteriis aliquid circa praedicta non petendo.

II. Item és estat pactat, avengut y concordat per y entre les dites parts que los dits doctors Juan Batiste Gil y Juan Batiste Caudí hajen de renunciar com ab lo present capítol renuncien a qualsevol dret que tinguen contra el dit Claustro per rahó dels gastos que han subministrat en adelantar lo procés y causa que dit Claustro, juntament ab los exami- 
nadors reals de medecina porta ab los examinadors reals del collegi de sirujans, y dit col.legi sobre el examen de dites comares, fent pacte, així real com personal, ab solemne stipulació, roborat de ulteriis aliquid non petendo en quant a dits gastos per aquells, en dit prosés et extra subministrats, absolent, com ab lo present absolen a dit Claustro de dites despeses inposant-se silenci y callament perdurable circa praedicta.

III. Item és estat pactat, avengut y concordat per y entre dites parts que per quant los dits doctors Juan Batiste Gil y Juan Batiste Caudl, havent examinat algunes comares de fora de la present ciutat, no pogueren cobrar en prompte les propines per la pobrea de aquelles y esterilitat del temps, per lo que se ajusta que cascuna de aquelles ferms una o ligacló a favor dels examinadors reals de lo que importava cascun examen, que per ço los dits doctors Juan Batiste Gil y Juan Batiste Caudí, hajen de cedir y transportar, segons que ab lo present capítol prometen cedir y transportar a dit Claustro tots los drets, part y porció que tenen en virtud de les dites obligacions, reservato iure als demés interesats en aquelles, com sa intenció dumtaxat, sia transferir en lo dit Claustro la part tocant a aquells y no més, les quals cantitats hajen de entrar en poder del depositari que lo dit Claustro huy te nomenat o en avant nomenarà.

IIII. Item és estàt pactat, avengut y concordat per y entre les dites parts que sempre y quant per alguna sutilitat de dret per part del dit Claustro o algú o alguns particulars de aquell, es pogués pretendre per algun temps que la present concordia no tingués validitat y execució respecte del dit Claustro, que en este cas quede in totum rescindida y aquells no estiguen tenguts a cosa alguna de lo promes en aquella, de forma que tot a1la que lo dit Claustro per la cesió fahedora de dites obligacions haura cobrat succehit lo dit cas haja de reshtuir y pagar en continent als dits doctors Juan Batiste Gil y Juan Batiste Caudí, con ab lo present ho prometen en dita conformitat.

V. Item és estat pactat, avengut y concordat per y entre les dites parts que lo present capítols y cascú de aquells, sien executoris ab sumició, renunciació de for, variació de juhí $\mathrm{y}$ altres in similibus posar acostumades.

Quibusquidem capitulis nobis lectis et publicatis et per nos bene intellectis serce cum praesentis praemisa capitula et omnia et singula superius contenta, facimus, laudamus, aprobamus, atque firmamus pro ut in eis et eorum quolibet continetur, promitimusque una pars nostrum alteri et altera, alteri in vicem et vicisim praedicta capitula et in eis et eorum quolibet contenta servare et adimplere pro ut ad nos respe. pertmet et spectat omnibus dilationibus etc. sub poena decem solidum etc. Qua poena etc. Ratto pacto etc. Ad quorum omnium etc. fiat executoria large etc. Cum fori submitione propii fori renuntiatione, variatione etc. Promitentes ac iuramentes ad Dominum Deum etc. non litigare neque impetrare etc. sub dicta poena etc. Qua poena. Ratto pacto etc. Proquibus etc. Obligamus una pars nostrum alteri, et altera alteri etc. Renuntiantes benefitiis cedendarum ac dividendarum actionem etc. novae constituioni de fideiusoribus etc epistolae divi Adrìani etc. foro Valentiae etc et omni alii etc. Actum Valentiae etc.

Testes fient Hyacintus Sanchis, alguacinius universitatis, et Hyacintus Acensi, studens, Valentia vicini.

Archivo del Corpus Christi. Notario Fulgencio Artich. Protocolo 5076.

Asclepio-Vol. XLV-1-1993 
Deliberación de los electos de medicina en el que se impone una tacha aprobada anteriormente a todos los nuevos graduados en medicina y a aquellos doctores extranjeros que se instalen en Valencia para ejercer la medicina.

\author{
Dictis die et anno (1.3.1692)
}

Anno a Virgineo partu millessimo sexcentesimo nonagesimo secundo, die autem primo, mensis martii intitulato. Juan Batiste Gil de Castelldases, Berthomeu Selma, Vicent Estruch, Martí Xalo, Gaudencio Senach y Gaspar Galindo, tots doctors en medicina y elets del Il.lustre Claustro de medecina de la present ciutat. En presència y asistència del doctor Thomas Velasques, prebere, vice-rector de dita Universitat, ajustats y congregats en la capella de nostra señora de la Sapiència, construida dins de dita Universitat, a hon per a semblans afers y negocis se solen y acostumen juntar, precehint convocació feta per Felip Ferrer, subdelegat de vedell de dita Universitat, lo qual mijansant jurament a nostre senor Déu Jesuchrist, etc. feu relació a mi lo notari infraescrit en presència dels testimonis inferius conteguts; haver convocat a tots los elets de dit I.llustre Claustro de orde de don Vicent Carros Pardo de la Casta, canonche de la Metropolitana Yglésia de la present ciutat, rector de dita Universitat per a els present puesto, dia y hora, ab comminació precisa de que ab los que estrobarien es poguesen fer qualsevols actes y deliberacions. Aserent ser la major part dels dits elets del Claustro de medecina. Attés que lo dit Claustro de medicina en junta general, ab acte rebut per lo notari infraescrit en deu de juny mil sis-cents huytanta y huit, delliberà que per quant lo dit Claustro seguia diferents pleyts considerables en defensa de algunes gracies, inmunitats, prerrogatives y preheminencies de que goza, y que per a acudir als gastos de aquells y altres extraordinaris, hauria estat precís el pendre dos cambis, cascú de propietat de cent lliures, a la satisfació dels quals y dels interesos no es podia acudir per no haver efectes promptes en lo Claustro, que per ço és, donàs poder com ab tot efecte el donaren als elets que lo dit Claustro tenia nomenats, per a que estos, o la major part de aquells, imposaren una tacha o derrama als particulars del dit Claustro, a cascú de la cantitat que els paregués proporcionat y convinent, que ab tot efecte imposaren ab acte rebut per Ignacio Avellaneda, notari, en vint y sis de setembre mil sis-cents noranta, modo et forma et ibi latius, y que de lo que importas aquella se acudís als gastos dels dits pleyts, y a la solució de dits cambis, y interesos; com a tot efecte es gastaren diferents cantitats en dits pleyts y se ha quitat un cambi dels desús dits y els interesos de aquells. Attés etiam que al present està devent encara lo dit Claustro lo altre de dit cambis, y que té alguns gastos precisos y necesaris a que accudir de pleyts y altres y que la cantitat de dita derrama no és bastant a satisfero, y que aprés de haverse fet dita derrama, alguns han obtés la gracia de doctor en medicina y altres han vengut a la present ciutat que entonces no estaven, los quals és just contribuixquen en dita derrama que ha de fer per a lo desús dit, pues no hia rahó que havent-se occasionat los dits empeños al Craustro, algunes inmunitats, gracies y privilegis defensant, com se ha dit, de les quals han degaudir, senten lo benefici, y no lo gravamen, áixí los que después de dita derrama se han graduat, y que han vengut a la present ciutat, com los que en avant se graduaran. Per ço, tots unànimes y concordes, y ningú discrepant, tenint poder com se ha dit del dit il.lustre Claustro scienter etc. cum praesenti etc. Dellibe- 
ren y determinen y imposen y señalen per tacha y derrama als doctors Francisco Escrig, Renualdo Balaguer, Domingo Martines, Carlos Verdú, Pere Juan Blanes, Joseph Navarro, Juseph Fauado, Esteve Aleigret y altres qualsevols graduats en aprés, y que han vengut a la present ciutat, en aprés de feta dita derrama a cascú de aquells dos lliures, moneda reals de València, que és. lo menys que los demés particulars del dit Claustro han pagat, y així mateix la dita cantitat a cascú dels demés que in eventum es graduaran y vindran a la present ciutat, que al present estan fora; la qual tacha, o derrama imposen aquells, y a cascú de aquells ab les mateixes calitats, clàusules, circuntancies y apremis que es contenen, així en lo dit acte rebut per lo dit Ignacio Avellaneda, notari infraescrit en deu de juny mil sis-cents huytanta y huit, les quals volen tenir así per repetides de verbo ad verbum brevier consulentes. Dequibus etc. Actum Valentiae etc. Presents foren per testimonis, Blay Querol y Joseph fuan estudiants de dita y present ciutat de València habitants.

Archivo del Corpus Christi. Notario Fulgencio Artich. Protocol 5077.

IX

Claustro general de medicina en el que se nombra electos y depositario del mismo.

Die XXIII mensis junii anno a Virgineo partu MDCLXXXXIII (23.6.1693)

Anno a Virgineo partu millessimo sexcentesimo nonagesimo tertio die autem intitulato vigessimo tertio mensis junii. Los doctors Juan Joseph Viñau, Juan Batiste Gil de Castelldases, Berthomeu Selma, Mathies Domingo, Juan Batiste Caudí, Esteve Falcó, Vicent Traver, Gaspar Felix Galindo, Antoni GiI, Bonaventura Viñau, Juseph Nebot, Francisco Jaume, Felip Carreres, Antoni Huson, Francisco Prebull, Juan Navarro, Vicent Meseguer, y Andreu de LLuguí, tots doctors en Medecina, de la present ciutat y sa contribució particular, ajustats y congregats en la Capella de Nostra Señora de la Sapiensia, construyda dins de la Universitat de la dita y present ciutat hon per a semblants afers, y negocis se solen, y acostumen juntar en virtut y execució de provició feta per lo reverent Geroni Castelló, prebere, doctor en sagrada theologia, vice-rector de dita Universitat ab cominació precisa que ab los que es trobarien presents es poguesen fer qualsevols actes, y deliberacions que convinguesen preseint convocació feta per Gaudencio Alvarado subdelegat de Jacinto Sanchis, alguazil de dita Universitat, el qual michansant jurament a nostre señor Déu etc. en mà y poder de mi lo notari infraescrit y en presensia dels testimonis prestat, feu relació haver convocat tots los doctors en medicina de la present ciutat, y sos arrabals per a els presents puesto, dia y hora, ab dita cominció. Tots unànimes, y concordes y ningú discrepant en presènsia y asistència del dit reverent vice-rector, revocant primerament sens nota alguna de infamia, si sols per a exoneració del treball que fins huy han tengut a tots los elets que tenien nomenats ab actes rebuts per lo notari infraescrit $y$ altres fins lo dia de huy, per a tractar diferents coses convenients al present Craustro: abdicant, y removent de aquells qualsevol poder en ses no-

Asclepio-Vol. XLV-1-1993 
minacions sels haja consedit scienter etc. tenore praesentis etc. nomenen y eleixen en nous elets del present Claustro als doctors Juan Batiste Gil de Castelldases, Esteve Falcó, Vicent Traver, Gaspar Felix Galindo, Antoni Huson, Felip Carreres presents, y a Juan Batiste Ferris absent per a tratar de les cobranses, així de la taicha que huy estan devent a dit Claustro alguns particulars de aquell, com de les cantitats que huy se estàn devent al dit Claustro dels examens de les Comares, lo dret de recobrar les quals e diner a favor de dit Claustro lo dit doctor Juan Batiste Gil, y Juan Batiste Caudí, y per a tractar, de estos effectes o, altres qualsevols donar satisfacçió, y pagar lo cambi de cent lliures que huy està devent lo dit Claustro que fonch prés per lo dit doctor Juan Batiste Gil, y el quondam doctor Felix Julià Rodrígues, y interesos de aquell, y així mateix per a nomenar depositari, en poder del qual entren les cantitats que es dehuen, y es deuran a dit Claustro per qualsevol rahó; y per a demanar contes als depositaris, y síndichs que han estat del dit Claustro fins lo día de huy, y ho seran en avant, y així per a trastejar si les propines, o, part de aquelles que es donen per los graduandos als catedratichs, y graduats per la asistència en lo theatro a les condusions, se aplicaràn per obs del dit Claustro,o, no, y per aquell temps que els pareixerà, y així, mateix per a trastechar lo modo més convenient per a extinguir les germandats, y que tinga validitat la deliberació que en temps propasat feu sobre aço lo dit Claustro, y últimament per a trastechar totes, y qualsevols altres coses, de qualsevol calitat que sien, consernents al bon govern, y utilitat del dit Claustro, donant-los a aquens, y a la major part de aquells, com a lo present los donen ple, y bastant poder per a que en rahò y sobre les dites coses y cascuna de aquelles puixen fer qualsevols actes, determinacions, y deliberacions que convinguen, y sien necesaries, ab qualsevols clàusules, y en la mateixa forma que el tenien concedit als altres elets, que tenient nomenats, en los actes de ses nominacions, de tal manera que no els falte poder algú, y puixen fer en e sobre tot lo desús dit, tot allo que el present Claustro llegítimament congregat pot fer promitentes etc. obligantes omnia bona dicti Claustri etc. Actum Valentiae etc.

Testes sunt Isidrus Reguillo, studens, et Joseph Marco, monitor, Valentiae, vicini.

Archivo del Corpus Christi. Notario Fulgencio Artich. Protocolo 5078.

$\mathbf{X}$

Deliberación de electos del Claustro de medicina en la que se nombra su depositario y normas relativas a la distribución de propinas por exámenes. Además se obliga a que los nuevamente graduados paguen las tachas aprobadas con anterioridad.

Dictis die et anno (26.06.1693)

Anno a virgineo partu millesimo sexcentesimo nonagesimo tertio, die autem intitulato vigessimo sexto, mensis junii. Juan Batiste Gil de Castelldases, Esteve Falcó, Vicent Traver, Gaspar Felix Galindo, Antoni Huson, y Felip Carreres, tots doctors en medicina, habitadors de la present ciutat de València, major part dels elets del Claustro de medecina 
de dita y present ciutat y sa contribució particular, ajustats y congregats en la Capella de nostra Señora de la Sapiència construida dins la Universitat de la present ciutat, a on per a semblants afers y negocis se solen y acostumen juntar, en presència y asistència del reverent Gaspar Domingo, prebere, canonge de la Metropolitana Yglésia de dita y present ciutat, rector de dita Universitat, consta de sa nominació ab acte rebut per lo notari infraescrit en vintitres del corrent, tenint poder per a les coses infraescrites, tots unànimes $y$ concordes, y ningú discrepant, y representat lo dit Claustro, scienter etc. cum praesentis etc. del.liberen y determinen les coses imediate següents.

Primerament del.liberen y determinen es nomene com ab lo present nomenen en depositari del dit Claustro al dit Juan Batiste Gil de Castelldases present y acceptant en poder del qual ajen de entrar y entren qualsevols cantitats que huy se li estiguen devent al dit Claustro, y en avant se li podran deure per qualsevol persones, així de la taicha y derrama que en temps propasat se imposa als particulars de aquell, com dels examen de les comares de fora, del dret de cobrar los quals, lo dit doctor Juan Batiste Gil y lo doctor Juan Batiste Caudí, feren cesió al dit Claustro en seguida de hu dels capítols de la concordia fermada entre parts de estos de una y lo dit Claustro de altra, los quals actes foren rebuts per mi lo notari infraescrit en dies propasats; y així mateix qualsevols cantitats que es deguen y puguen deure així de les propines dels graus que se han aplicat per a obs del Claustro, segons altra del.liberacio feta per dits elets en lo dia de huy, com de resagos de les propines del hort de erves medicinals, y totes y qualsevols altres cantitats que per qualsevol causa, motiu o rahó, qualsevol que sia se li deguen y puguen deure al dit Claustro, y de lo que cobrarà, puixa fermar qualsevols apoches, albarans y cauteles, donant-li acerca de lo desús dit, tot lo poder que convinga, y sia necesari, prometent en dit nom etc. obligant los béns de dit Claustro etc. .

Item, del.liberem y determinen que de huy en avant de cascun grau de doctor que es farà, de aquells quatre reals de propina que sels dona a cascú dels catedràtichs y dos reals a cascú dels graduats que asistixen a les conclusions, sols sels done, ço és, a cascun catedràtich, dos reals y a cascú dels graduats un real, y que els altres dos reals que els tocaven a cascun catedràtich y lo altre real quels tocava a cascú graduats asistens, tinguen obligació lo graduando y son president, de depositar-los en poder del Prior que serà de dit Claustro, y este entregar-los al depositari desús nomenat y quel serà en avant, y que estes cantitats, se apliquen per a satisfer lo cambi de cent lliures y interesos que huy se està devent per dit Claustro, pres per lo dit doctor Gil y el quondam doctor Felix Julià Rodriguez, y que aso sols tinga son degut efecte fins tant ab tot efecte lo dit Claustro habra satisfet de estos effectes, y altres dit cambi y interesos, y que pagat cese la present del.liberació, y que de en la mateixa forma que estava aixi de ferse esta.

Item per quant ab acte rebut per lo notari infraescrit en lo primer de mars mil sis-cents noranta dos, los elets que entonces eren de dit Claustro per les causes en dit acte contengudes del.liberaren que els doctors que aprés de la última tacha y derrama que se imposa als particulars del dit Claustro vinguesen a la present ciutat, o en graduasen novament paguasen dos lliures de tacha cascú de aquells, que era la més modica que sels havia posat als altres, y que estes se depositasen en poder del depositari del dit Claustro; ara volent quede en sa forsa y valor dita del.liberació y sols per a millorar aquella, del.liberen y determinen que els que de huy en avant es graduaran de bachiller, hachen de pagar una lliura de tacha cascú y altra lliura cascú que es graduarà de doctor, fent deposit uns y altres de aquelles en poder del Prior del dit Claustro al temps que farà el deposit del grau, y que en cas de obte- 
nir los dos graus a un temps hacha de fer deposit de dos lliures en la mateixa forma, una per cascun grau y que el dit Prior les entregue en aprés al depositari que serà de dit Claustro per a que estes cantitas serveixquen també per a quitar lo dit cambi, y en aprés per a gastos ordinaris y extraordinaris de dit Claustro, que convinguen y sien necesaris de quibus etc. Actum Valentiae etc. Praesentis foren testimonis Geroni Hugo, apuntador de dit Universitat y Francisco Loret, practicant de medecina, de València abitadors.

Archivo del Corpus Christi. Notario Fulgencio Artich. Protocol 5078

\section{XI}

Claustro general de medicina en el que se delibera que los médicos no catedráticos tengan médicos en prácticas.

\section{Dictis die et anno (03.08.1693).}

Nos Berthomeu Selma, Juan Batiste Gil de Casteldases, Juan Batiste Caudí, Mathias Domingo, Esteve Falcó, Juan Batiste Ferris, Francisco Durbà, Gaudencio Senach, Martí Xalo, Gaspar Galindo, Antoni Uson, Jusep Antoni Gil, Bonaventura viñau, Basilio Corella, Felip Carreres, Pere Juan Blanes y Ignacio Paches, tots doctors en medicina de la present ciutat, y del Claustro de aquella, ajustats y congregats en la Capella de nostra Señora de la Sapiència construida dins de la Universitat de la dita y present ciutat ha on per a semblans afers y negocis se solen y acostumen juntar, en virtud de provisió feta per lo reverent Geroni Castelló, prebere, doctor en Sagrada Theologia, vice-rector de dita Universitat, ab comvocació presisa de que ab los-que es trobarien presents es pogueren fer qualsevols actes y del.liberacions, presehint convocacio feta per Gaudencio Alvarado, subdelegat de Alguazil de dita Universitat, el qual michansant jurament a nostre Señor Déu etc. en mà y poder del notari infraescrit prestat, feu relació haver convocat a tots los dotors en medicina de la present ciutat per a el present puesto, dia y hora, y ab dita.cominació en presència y asistència del dit reverent vice-rector, havent-se proposat es faria Syndicat y poder a favor del dit doctor Juan Batiste Ferris per a fermar de dret en e sobre la poseció en que estàn los metges graduats de dits Claustro que no són Chatedratichs, de tenir placticans y ser admesos estos al grau, així de bachiller com machor de dita facultat, trobant-los habils y de cobrar los mestres en qui han tengut la pràctica certa propina y altres qualsevols posecions de qualsevols preheminències, béns y drets, en que està lo dit Claustro; es pasa a votar y foren trobats deu vots que sí y set que no, per lo que lo dit Claustro ab la dita machor part de vots y per ell tots los desús dits que el representen, scienter etc. cum praesenti etc. fan y costituixen etc. en syndich y procurador de dit Claustro verdader y cert etc. Ita quod etc. al dit dotor Juan Batiste Ferris habitador de València present etc. per a que en nom de dit Claustro sobre la poseció seu quasi que huy té o en avant podrà tenir de qualsevol béns, drets, prerrogatives y preheminències $\mathrm{y}$ altres qualsevols coses de qualsevol gènero, especie y calitat que siguen, puixa fermar de dret així en la Real Audiència, com en la Gobernació, Justicia Civil, y altres qualsevols tribunals y en poder de qualsevols jutjes y officials de la dita y present Ciutat de València 
contra qualsevols persones, Colegis, universitats, comunitats y altres qualsevols gremis, per qualsevols causes y rahons, y per a asso qualsevols fermes y contrafermes de dret, posar y presentar y prometre en nom del dit Claustro estàr a dret, fer dret, y pagàr cosa juchada, fent qualsevols obligacions ab totes les clàusules executives, penals, submissió, renunciació de for, variació, y demes guarentígies oportunes y necesaries, a ell ben vistes prestar, y oferir qualsevols causcions, y principals obligats, juntament ab lo dit Claustro, sens ell, y a soles ben guardar, los indemnes y per a tot lo desús dit hypoteque, y obligue tots los béns y drets de dit Claustro etc. y a tots los pleyts large etc., cum posse substituendi circa omnia etc. promitentes etc. obligantes omnia bona dicti Claustri etc. y trobant-se presents los que foren de contrari parer que foren los doctors Berthomeu Selma, Juan Batiste Gil, Mathias Domingo, Gaudencio Senach, Jusep Antoni Gil, Antoni Uson, y Martí Xalo, y lo dit Uson no sols en nom de Catedratich, si també en nom de Procurador dels demés Catedràtichs de dita facultat, protestaren en primer lloch, el que no es pleyteje ni gaste sobre lo desús dit, per ser pleyt injust, y contra deliberació del Il.lustre Claustro machor, y en segon lloch, la present elecció y nominació de Syndich per a fermar de dret y prestar caució, y qualsevols gastos que se oferixquen fer en qualsevols pleyts que sobre aso es pugen moure, y que dits gastos no es puixen traure de lo comú de dit Claustro, ni per si ells protestants volen estar tenguts a pagar cosa alguna, protestànt la narrativa que es fa en la proposta de que estarien los doctors graudats que no són Catedratichs en la poseció que allí se insinua, per no tenir aquella si sols los Catedratichs, volent que tots sos drets los resten salvos, e ilesos in omnibus, et per omnia, y tots los demés que vingueren bé en fer lo present syndicat contraprotestaren per sí, y per tots los ausents graduats del dit Claustro que no són Catedràtichs, de tot ço e quant los sia llísit, y permés protestar, et precique de que los Catedràtichs de medecina per sí a soles compongen Claustro de dita facultat, per que qui el compon son no sols els Catedràtichs, si també tots los graduats, volent ser ad in vicem los últims en protestar per a salvetat de sos drets respectivament de quibus etc. Actum Valentiae etc.

Testes sunt Hyacintus Borras et Franciscus Sales, studentes Valentiae Vicini.

Archivo del Corpus Christi. Notario Fulgencio Artich. Protocolo 5078.

XII

Claustro general en el que se aprueba que las cantidades gastadas en los pleitos seguidos sobre la posesión que tienen los médicos no catedráticos de tener practicantes, se tomen de los fondos de dicho claustro.

Dictis die et anno (03.08.1693)

Anno a Virgineo partu millessimo sexcentesimo nonagesimo tertio, die autem intitulato tertio, mensis augusti. Berthomeu Selma, Juan Batíste Gil de Castelldases, Juan Batiste Caudí, Mathias Domingo, Esteve Falcó, Juan Batiste Ferrís, Francisco Durbà, Gaudencio Senach, Martí Xalo, Gaspar Galindo, Antoni Uson, Jusep Antoni Gil, Bonaventura Viñau, Basilio Corella, Felip Carreres, Pere Juan Blanes, y Ignacio Paches, tots doctors en medeci- 
na de la present Ciutat y del Claustro de aquella, ajustats, y congregats en la Capella de nostra Señora de la Sapiència, construhida dins la Universitat de dita y present Ciutat, ha on per a semblants afers y negocis se solen y acostumen juntar, en virtud de provició feta per lo reverent Geroni Castelló, prebere, doctor en Sagrada Theologia, vice-rector de dita Universitat, ab cominació presisa de que ab los que es trobarien es poguesen fer qualsevols actes, y del.liberacions, precehint convocació feta per Gaudencio Alvarado, subdelegat de Alguazil de dita Universitat, el qual michansant jurament a nostre Señor Déu etc. en mà y poder del notari infraescrit prestat, feu relació haver convocat a tots los doctors en medicina de la present ciutat, per a el present puesto, dia, y hora, y ab dita cominació, en presència y asistència del dit reverent vice-rector: havent-se proposat si es donaria facultat al dit doctor Juan Batiste Ferris per a gastar tot lo que convinga així en lo pleyt de ferma de dret, com en altres qualsevols moguts y que es poden moure sobre la poseció en que estan los metjes graduats que no són Catedràtichs de tenir practicans, y de que estos sien admesos als graus de bachiller y machor de dita facultat, trobant-los habils y de cobrar los mestres les propines que els toquen; es vota y foren atrobats deu vots afirmatius, y set negatius, per lo que la machor part de vots representant lo dit Claustro del.liberen y determinen se li done poder y facultat al dit doctor Juan Batiste Ferris per a que puixca gastar tot lo que convinga en tots los pleyts moguts y que es mouran sobre lo desús dit, y que tot allò que constara, haver gastat en dits pleyts ab llegítims cauteles, se li prenga en conte y se li pague en continent dels efectes que y haja en poder del depositari del dit Claustro, o se hajen de cobrar y es deguen al dit Claustro, y per a este efecte se impose derrama, si serà menester. $Y$ trobant-se presents los que foren de contrari parer que són los doctors Berthomeu Selma, Juan Batiste Gil, Mathias Domingo, Gaudencio Senach, Jusep Antoni Gil, Antoni Uson, y Mari Xalo, y lo dit Uson aixi en nom de Catedràtichs, com també com de procurador dels demés Catedràtichs, protestaren la present del.liberació, y tot lo contengut en aquella en la mateixa forma, y per les mateixes rahons contengudes en lo protest fer per aquells en lo acte rebut per lo notari infraescrit en lo dia de huy, poch ans del present, lo qual volen tenir assí per repetit de verbo ad verbum, brevitati consulens, y tots los demés que vingueren bé en la present del.liberació per sí, y per tots los ausents graduats contraprotestaren de tot ço et quant los sia llísit y permés protestar, volent ad vivicem ser los últims per a salvetat de sos drets, respective de quibus etc. Actum Valentiae etc. Presents foren per testimonis Jacinto Borras y Francisco Sales, estudiants de dita ciutat de València, vehins y habitadors.

Archivo del Corpus Christi. Notario Fulgencio Artich. Protocolo 5078.

\section{XIII}

Deliberación de los electos de medicina en la que se aprueban las cuentas presentadas por el depositario del claustro.

Die quinto mensis septembris anno a virgineo partu MDCLXXXXIII (5.9.1693)

Anno a Virgineo partu millesimo sexcentesimo nonagesimo tertio, die autem intitulato quinto, mes septembris. Juan Batiste Ferris, Esteve Falcó, Gaspar Felix Galindo, Pere 
Vicent Traver, Antoni Usson, y Felip Carreres, tots doctors en medecina, habitadors de la present ciutat de València, elets del Claustro de la medecina de dita y present Ciutat, ajustats, y congregats en la Capella de nostra Señora de la Sapiència, construida dins la Universitat de dita ciutat, aserent y afirmant ser la major part dels elets de dit Claustro, tenint poder de este por a lo infraescrit, pasaren a demanar compte al Doctor Berthomeu Selma, depositari que ha estat de dit Claustro de les pecunies que aurien entrat en son poder y en continent es pasa a fermar lo càrrech y descàrrech en lo modo y forma seguent.

\section{Càrrech}

Primo, es fa càrrech que cobrà del doctor Juan Viñau, sis lliures per la derrama que imposà lo dit Claustro als particulars de aquell.......... ltem es fa càrrech que cobrà del quonaam doctor Felix Julia Rodrigues, sis lliures per dita rahó

6 Liures Item es fa càrrech que cobrà del doctor Miquel Noguera sis lliures, per dita rahó

Item es fa càrrech que cobrà del doctor Gaspar Regal, sis lliures per dita rahó.....

Item es fa càrrech que cobrà del doctor Juan Bautiste Caudí, sis lliures, per dita rahó.

Item es fa càrrech que cobrà del doctor Vicent Estruch, sis lliures per dita rahó

Item es fa càrrech que cobrà del doctor Pere Vicent Traver, sis lliures, per dita rahó

Item es fa càrrech que cobrà del doctor Jusep Navarro sis lliures per dita rahó

Item es fa càrrech que cobrà del doctor Gaudencio Senach, sis lliures per dita rahó

Item es fa càrrech que cobrà de ell mateix, sis lliures per dita rahó.... Item es fa càrrech que cobrà del doctor Mathias Domingo, sis lliures per dita rahó

Item es fa càrrech que cobrà del doctor Martí Xalo, sis lliures per dita rahó

Item es fa càrrech que cobrà del doctor Felip Alfaví, sis lliures per dita rahó

Item es fa càrrech que cobrà del doctor Francisco Estelles, sis lliures per dita rahó

Item es fa càrrech que cobrà del doctor Jesualdo Catarroja, sis lliures per dita rahó

Item es fa càrrech que cobrà del doctor Francisco Durbá, quatre lliures per dita rahó

Item es fa càrrech que cobrà del doctor Antoni Usson, quatre lliures per dita rahó.

Item es fa càrrech que cobrà del doctor Miquel Lapis, quatre lliures per dita rahó..... 
Item es fa càrrech que cobrà del doctor Felip Carreres, quatre lliures per dita rahó

4 Liures

Item es fa càrrech que cobrà del doctor Jusep Calbo, quatre lliures per dita rahó.

Item es fa càrrech que cobrà del doctor Francisco Jaume, quatre lliures per dita rahó

4 Liures

Item es fa càrrech que cobrà del doctor Esteve Falcó, dos lliures per dita rahó.....

Item es fa càrrech que cobrà del doctor Bonaventura Viñau, dos lliures per dita rahó.

Item es fa càrrech que cobrà del doctor Miquel Lumbier, dos lliures per dita rahó....

Item es fa càrrech que cobrà del doctor Francisco Peres, dos lliures per dita rahó

Item es fa càrrech que cobrà del doctor Thomas Ballester, dos lliures per dita rahó.

Item es fa càrrech que cobrà del doctor Jusep Nebot, quatre lliures per dita rahó

Item es fa càrrech que cobrà del dit doctor Miquel Noguera, dotse lliures, catorse sous, per tantes ne devia a dit Claustro com a Prior que hauria estàt de aquell, de resago de propines ...

.....12 Liures 14 sous

Item es fa càrrech que cobrà de una comare per un examen dels dits, al dit Claustro, quatre lliures

4 Liures

Totes les quals partides de càrrech acomulades, prenen summa universal de cent quaranta quatre lliures y catorse sous.

Descàrrech

Primo dona en descàrrech que pagà al doctor Gaspar Felix Galindo, syndich del Claustro, sis lliures per a gastos dela Plasa, com consta per albarà fermat de la sua mà ...

6 Liures

Item dona en descàrrech, que pagà al dit Galindo per a lo mateix dotse lliures catorse sous com consta ab albarà fermat de la sua mà..12 Liures 14 sous Item dona en descàrrech que pagà al dit Galindo, per a lo mateix setse lliures, com consta ab albarà fermat de la sua mà ..

16 Liures

Item dona en descàrrech que pagà al notari infraescrit y a Ygnacio Avellaneda, cinch lliures per los treballs que haurien tengut en asistir al Claustro com consta ab albarà fermat de les sues mans

5 Liures Item dona en descàrrech que pagà al doctor Gaudencio Senach una lliura dihuit sous com consta ab albarà de la sua mà ... 1 Liures 18 sous Item dona en descàrrech que pagà al doctor Vicent Armengol de Folch, advocat del Claustro, deu lliures a conte de sos treballs com consta ab la apoca fermada per a aquell y dos sous de dita apoca ...... 10 Liures 2 sous 
Item dona en descàrrech que pagà al vedell de dita Universitat setse sous per la convocació per a junta general del Claustro consta ab albarà de la sua mà

Item dona en descàrrech que pagà al dit doctor Vicent Armengol advocat de dit Claustro cinch lliures a conte de sos treballs com consta ab albarà de la sua mà

Item dona en descàrrech que pagà a Francisco Remury, especier, vinty quatre lliures per huit fires dels interesos de un cambi de cent lliures que te donades a alguns particulars del Claustro per a obs de este, com consta ab apoca fermada per aquell y dos sous de dita apoca

Item dona en descàrrech que pagà a Jusep Peris, ciutada, vinty set lliures per nou fires dels interesos de un cambi de cent lliures que tenia donat a alguns particulars de dit Claustro per a obs de este com consta per los retorns de dites fires.

Item dona en descàrrech que pagà al dit Peris, trenta una lliures a cumpliment de les cent lliures del dit cambi, y interesos, com consta $\mathrm{ab}$ apoca fermada per aquell, y dos sous de dita apoca

Totes les quals partides de descàrrech acumulades, prenen summa universal de cent trenta nou lliures setse sous, les quals rebaixades de les dites cent quaranta quatre y catorse sous que importa lo càrrech resta deutor lo dit doctor Selma al dit Claustro de quatre lliures dihuit sous, les quals confesen haber hagut y rebut de aquell realment y de contans et quia etc. renunciaren etc. y per ço tots unànimes, tenint poder de dit Claustro scienter etc. cum praesenti etc. ab solgueren y definiren al dit doctor Selma, present y als seus, una cum bonis etc. liberando illum etc fet pacte real y personal de ulterius aliquid non petendo inposant-se silenci, y callament perdurable prout melius etc. salvo semper quocumque errore recti calculi promitentes etc. facere, habere, tenere etc. proquibus etc. obligamus omni a bona dicti Claustri etc. Actum Valentiae etc. Presents foren per testimonis Juan Puchal, fuster, y Bernat Lamarca, lacayo, de dita y present ciutat de València, vehins y habitadors.

Archivo del Corpus Christi. Notario Fulgencio Artich. Protocolo 5078.

XIV

Deliberación de los electos de medicina por el que se aprueba librar una letra de cambio con el objeto de sufragar diferentes gastos.

Die V mensis februarii anno a virgineo partu MDCLXXXXIIII (5.2.1694)

Anno a virgineo partu millessimo sexcentesimo nonagesimo quarto, die autem intitulato quinto, mensis februarii. Juan Batiste Ferris, Esteve Falcó, Gaspar Felix Galindo, Pe-

Asclepio-Vol. XLV-1-1993 
re Vicent Traver, Antoni Uson y Phelip Carreres, tots doctors, en medecina, habitadors de València, elets del Claustro de dita facultat, ajustats y congregats en la Capella de Nostra Señora de la Sapiència, construida dins de la Universitat de dita y present ciutat, a hon per a semblants afers y negocis se solen y acostumen juntar, asserent y afirmant ser la major part de dits elets nomenats per lo dit Claustro ab acte rebut per lo notari infraescrit en vint $\mathrm{y}$ tres de juny propasat, tots unànimes y concordes y ningú discrepant, tenint poder per a lo infraescrit. Atés y conciderat que lo dit Claustro seguex un procés per la Real Audiència en juhí de supplicació, sots audició del magnífich Luis Pastor y Beltran, D.D.R.C., del qual és escriva Francisco Sanchiz notari en e sobre la decretació, que supplica de del.liberació feta per dit Claustro, per a extinssió de les conduccions que alguns meches fan ab algunes germandats de la dita y present ciutat, y també que se han de moure alguns pleyts contra alguns graduats y hereus de altres per a exacció de diferents cantitas que per aquells se dehuen a dit Claustro de resagos de les propines del hort de herves medicinals que sa Magestat adjudica al dit Claustro per a gastos de aquell, y altres tocans y respectans a la conservació de dit hort, per a el qual efecte sa Magestat ha estat servit nomenar en Jutge Real comisari al noble Don Lorens Matheu y Villamayor D.D.R.C. y per a tot aço no hia efectes promptes alguns per a poder subministrar los gastos que se oferiran. Per ço los dit elets unànimes y concordes y ningú discrepant, tenint poder com se ha dit per a lo infraescrit així en dit acte rebut per lo notari infraescrit com per lo rebut per Víctor de Salafranca, notari en tretse de juny mil sis-cents huitanta y tres, ab lo present del.liberaren y determinaren que per a acudir als gastos, tansolament de dits pleyts y no de altres es prenguesen cinquanta liures a cambi, de la persona que les voldrà donar per a qualsevol fira, ab qualsevol sotascrita en un contracte o més y que estes se entreguen al doctor Juan Batiste Gil de Castelldases, depositari que és del dit Claustro per a que este, de dita cantitat subministre los gastos que se oferiran en dits pleyts tansolament y no en altres, com se ha dit, de manera que dita cantitat no es puixa aplicar a altra cosa que als dits gastos. Dequibus etc. Actum Valentiae, presents foren per testimonis Batiste Alagon, escrivent de València y Joseph Mañes, de la vila de Altura, respectivament habitadors.

Archivo del Corpus Christi. Notario Fulgenci Artich. Protocolo 5079.

XV

Aprobación por los electos de medicina de las cuentas presentadas por el depositario del claustro.

Die X mensis septembris anno a Virgineo partu MDCXCV (10. 9.1695)

Anno a Virgineo partu millesimo sexcentesimo nonagesimo quinto, die vero intitulato decimo, mensis septembris. Los doctors Joan Batiste Ferris, Pere Vicent Traver, Gaspar Felix Galindo, Antoni Uson y Felip Carreres, habitadors de València, major part dels elets del Claustro de medicina de la present ciutat, ajustats y congretas en la casa del rector de la Universitat de dita y present ciutat, en presència y asistència del Noble Don Francisco Monsoriu, prebere, sacriste de la Santa Metropolitana Yglésia de la mateixa ciutat, Rector de dita Universitat, tenint poder del dit Claustro de medicina especial per a lo infraescrit, com consta per les comunicacions fetes a son favor, rebudes per Victor de Salafranca y el 
notari infraescrit en tretse de juny mil sis-cents huitanta y tres y vintytres de juny mil siscents noranta y tres. Los quals així junts pasaren a demanar contes al doctor Joan Batiste Gil de Castelldases, depositari del dit Claustro nomenat ab acte rebut per dit infraescrit notari en vintysis de juny mil sis-cents noranta y tres; qui present estava de totes les cantitats que han entrat en son poder propries del dit Claustro procehides de qualsevols efectes, com de lo pagat per conte del dit Claustro desde dit temps fins lo dia de huy, ohida la qual requesta lo dit doctor Juan Batiste Gil pasa a donar los dits contes formant càrrech $\mathrm{y}$ descàrrech en, e per la forma seguent.

\section{Càrrech}

Primo. es fa càrrech de sis lliures que cobrà per lo repartiment antich dels doctors Amat, Planes y Cautí.

6 liures

Item es fa càrrech de huit lliures que cobrà per lo grau del doctor Bernia en lo Priorat del doctor Martí Xalo.

Item es fa càrrech de trenta quatre lliures per tretse graus de Bachiller y tres de doctor del Priorat del dotor Gaudencio Senach, com consta per dit llibre.

Item es fa càrrech de cent huit lliures que cobrà de Jesualda Orivay hereva del quondam doctor Juan Battiste Orivay, ab àpocha rebuda per lo notari infraescrit en nou dels correts, per les propines depositades en poder de aquell en los anys que fonch Prior de dita facultat

Item es fa càrrech que cobrà del doctor Berthomeu Selma dos lliures dihuit sous per tantes en que fonch alcansat en los contes que dona este del temps que fonch depositari del dit Claustro.

Item es fa càrrech de cinquanta lliures que se li entregaren en dihuit de febrer de mil sis-cents noranta y quatre per tantes que dits elets ne prengueren a cambi en dit nom per a obs del dit Claustro de Leonardo Lita, ab sota escrita del dit doctor Joan Battiste Perris ab actes rebut per lo dit e infraescrit notari en cinch de febrer mil siscents noranta y quatre.

Ultimo es fa càrrech de huitanta lliures que cobrà de vinty quatre graus de bachiller y huit de doctor en lo Priorat del doctor Joseph Antoni Gil com consta per dit llibre.

Totes les quals partides de càrrech acumulades prenen summa universal de dos-centes huitanta huit lliures y dihuit sous.

\section{Descàrrech}

Primo. dona en descàrrech que pagà al dit doctor Gaspar Felix Galindo, síndich del Claustro per a gastos de plasa ab albarà de la sua ma de vin de juliol mil sis-cents noranta y tres, de quatre liures......... 
Item dona en descàrrech dotse lliures que pagà a Francisco Remoy per les fires dels mesos de febrer, maig, agost y nobembre, mil siscents noranta y dos, per rahò de aquelles cent lliures que prengué a cambi lo dit doctor Gil y el quondam doctor Felix Julià Rodrigues, per a obs de dit Claustro com consta $a b$ àpocha rebuda per dit e infraescrit notari en huit de agost mil sis-cents noranta y tres, $\mathrm{y}$ els retorns, $\mathrm{y}$ dos sous de la àpocha lo qual cambi prengueren ab acte per Gaudencio Gasull en denou de octubre mil sis-cents huitanta y huit

12 liures 2 sous

Item dona en descàrrech una lliura dos sous que pagà al dit doctor Felip Carreres per un llibre de conte y rahó que es compra per a les cosses de dit Claustro

Item dona en descàrrech dotse sous que pagà al bedell del estudi per una convocació de Claustro feta en quinse de setembre mil sis-cents noranta y tres

Item dona en descàrrech que pagà al dit Bedell dotse sous per altra convocació de Claustro feta en trenta de Octubre dit any

Item dona en descàrrech que pagà al dit Francisco Remoy dotse lliuresper les fires de febrer, maig, agost, y novembre mil sis-cents noranta y tres, per rahò de dit cambi, consta ab apoca rebuda per dit, e infraescrit notari en dotse de nobembre dit any y dos sous de àpocha

Item dona en descàrrech que pagà a Feliciano Blasco escrivent del doctor Armengol, una lliura tres sous per diferents ordenates que havia escrit en los processos del Claustro ab albarà fet en dihuit de febrer mil sis-cents noranta y quatre

Item dona en descàrrech tres lliures quatre sous, y quatre dinès, que esperderen en cinch lliures catorse sous de dines roins que troba en les cinquanta lliures que se li entregaren del últim cambi .......

Item dona en descàrrech que pagà al dit Bedell per una convociació de Claustro feta en vintyset de agost mil sis-cents noranta y quatre dotse sous

Item dona en descàrrech que pagà al dit dotse sous per altra convocació de Claustro feta en trenta de setembre dit any.

Item dona en descàrrech que pagà al quondam doctor Vicent Armengol, advocat de dit Claustro, deu lliures a conte dels treballs per aquell subministrats en les causes de aquell, conferències, y resolutories, consta $a b$ àpocha rebuda per dit e infraescrit notari en sis de febrer mil sis-cents noranta quatre

Item dona en descàrrech que pagà a dit infraescrit notari altres deu lliures a conte dels treballs que aquell havia tengut per rahó de dit Claustro, consta ab àpocha rebuda per ell mateix en dit dia

Item dona en descàrrech que pagà a Francisco Sanchis notari set lliures per lo dret de procés de decret per a extinguir les germandats, consta ab albarà fet en sis de febrer mil sis-cents noranta quatre .......

1 liura 2 sous

12 sous

12 sous

12 liures 2 sous

l liures 3 sous

31.4 s. 4 d

12 sous

12 sous

10 liures

10 liures

7 liures 
Item dona en descàrrech que pagà als dits doctors Galindo y Ferris, deu sous a cascú, per un acte de nominació de elets, y per a pagar al corredor lo treball de haver buscat dites cinquanta lliures, consta ab albarà fet a dotse del antesedent

Item dona en descàrrech que pagà al dit doctor Galindo, quatre lliures per a gastos de plaza ...

1 liura

Item dona en descàrrech que pagà setse sous per la copia de una sentència

Itein dona en descàrrech que pagà al dit Remoy sexanta cinch lliures, ço és cinquanta lliures a conte de les cent lliures de dit cambi, y quinse lliures per les quatre fires del any mil sis-cents noranta y quatre y de la de dos de febrer mil sis-cents noranta y cinch, consta $a b$ àpocha per dit e infraescrit notnri en quatre de febrer propasat, y per los retorns y dos sous del àpocha

65 liures 2 sous

Item dona en descàrrech cinquanta sis lliures que es retura vers si, ço és, cinquanta lliures per a pagar al dit Remoy, restants de la propietat de dit cambi, y les sis lliures per dos fires que han discorregut. Item dona en descàrrech que pagà al doctor Alexandre Arboreda deu lliures a conte dels treballs que ha tengut per dit Claustro com advocat que és de aquell, consta ab albarà fet en vintytres dels corrents.....

Item dona en descàrrech que pagà a dit e infraescrit notari lliures a conte dels treballs que ha tengut per dit Claustro com síndich de aquell, consta ab albarà fet en dit dia

Item dona en descàrrech que pagà al dit doctor Juan Batiste Ferris, cinquant nou lliures, ço és, cinquanta lliures per la propietat del dit últim cambi, pres per dits elets del dit Leonardo Lita, y nou lliures per los interesos discorreguts fins la fira del present mes inclusive, lo qual pertanygue al dit Ferrís, per haver-lo pagat com a sota escrita, consta $\mathrm{ab}$ àpocha per dit $\mathrm{e}$ infraescrit notari en vint $\mathrm{y}$ tres dels corrents y dos sous de la àpocha...

Item dona en descàrrech que pagà al doctor Ferris, set lliures quatre sous per diferents gastos que aquell a subministrat per dit Claustro com a Síndich de aquell, així en los processos que porta com en traure alguns actes que han estat menester, consta ab albarà fet en dit dia . . .

Totes les quals partides de descàrrech acumulades prenen en suma universal de doscentes setanta y quatre lliures cinch sous y quatre dines. Les quals rebaixades de les doscentes huitanta huit lliures, y dihuit sous que importa lo càrrech, resta deutor lo dit doctor Gil de catorse lliures dotse sous, y huit dines, les quals estant lo dit doctor Gil present, confessa tenir en son poder com a propies de dit Claustro a tota orde y disposició de este. Per lo que los dits elets ab lo poder que tenen del dit Claustro absolen y difinixen a aquell present etc. y als seus de dits contes, confessant haver donat bo y llegítim conte y restar deutor de dites catorse lliures, dotse sous, y huit dines y haver entregat totes les apoches y cauteles en lo descàrrech mensionades sent pacte de ulterius aliquid non petendo sive de 
non agendo eta. Imposant silenci perpetuo a dit Claustro eta. salvo semper quocumque errore recti calculi. Intellectis eta. Proquibus etc. obligaren los bens de dit Claustro etc. Actum Valentiae etc.

Testes sunt Joseph Rosales studens, et Hieronimus Sadorni, urgarius Valentiae vicini.

Archivo del Corpus Christi. Notario Fulgencio Artich. Protocolo 5080.

\section{XVI}

Claustro general de medicina en el que se nombran tres nuevos electos con poder para elaborar unas nuevas constituciones.

Die III Augusti Anno a nativitate domini MDCLXXXXVIII (3.8.1698)

Anno a nativitate domini millessimo sexcentessimo nonagessimo octavo, die vero numerato tertio, mensis augusti. Vicent Domingo, prebere, canonge de la Metropolitana Isglésia de la present ciutat de València, vice-rector de la Il.lustre Universitat, els doctors Juan Batiste Gil de Catelldases, Juan Batiste Ferris, Estheve Falcó, Francisco Durbà, Christofol Frayle, Martí Xalo, Gaspar Galindo, Juseph Cantí, Juseph Nebot, Felip Carreres, Thomas Longás, Salvador Perez, Estheve Alegret, Bonaventura Binau, Macià Aznar, Miquel Sogobia, Francisco Llorenç, Antony Beltran, Vicent Bartolla, Jaume Sanz, Juan Bahste Frayle, Juseph Cases, Antony Seguer, Felip Sereso, Francisco Lloret, Manuel Blasco, y Juseph Cano, tots metges graduats del grau de medicina en la Universitat de dita Il.lustre ciutat, ajustats y congregats en la Capella de la Sapiència, construhyda dins dita Universitat, hon per a semblants afers y negosis es solen y acostumen ajustar, y congregar, precehint convocació feta per Gerony Sadoini, subdelegat de Francisco Beltran, vedell de dit Estudi General, el qual com fos present feu relació michansant jurament a nostre señor Déu Jesuchrist etc., en mà y poder del notari infrascrit, prestà ell haver convocat a tots los metges graduats del grau de medicina per a els presents puesto, dia y hora, affermant, ésser la machor part de aquells, y tot lo dit Il.lustre Claustro de medicina representants, tots unànimes y concordes, y ningú discrepant (exceptant el doctor Francisco Durbà, el qual dix que no huy consent en la present nominació). Proveheixen, del.liberen y determinen, y ab lo present nomenen en elets als doctors Juan Batiste Gil, doctor Juan Batiste Ferris, y al doctor Gaspar Galindo, de la present ciutat de València, vehins y habitadors, presents y acceptànts per a que en nom de dit Il.lustre Claustro de medicina y representant aquell puguen elegir y nomenar dos advocats, los que adaquells los pareixerà, y ab intervenció de aquells, formen les constitucions que els pareixera ser convenients y necessàries per a el bon govern y administració de dit Il.lustre Claustro de medicina, y enseguida de estar formades les hatjen de conferir y confereixquen a tot lo Il.lustre Claustro, per a que en vista de aquelles, puixa aprobar, reprobar, añadir o millorar, y altres de nou elegir, y de aquelles suplicar a sa Magestat (que Déu guarde) la aprobació y confirmació, interposant sa real authoritat, per resultar, com resultaran, en gran beneffici de la Il.lustre ciutat y bon govern de dit Il.lustre Claustro de medicina, per el qual effecte donen po- 
der y facultat als referits elets per a que puguen subministrar el gasto que se oferirà y serà convenient, volent que accerca de lo referit no els falte poder algú. Prometteren etta. obligaren etta. De totes les quals cosses em requeriren a mi Antony Xavar, notari públich de la ciutat y Regne de València, los ne rebera charta pública, per a haverne memòria en lo esdevenidor, y per a els effectes que més y millor de justícia los convingues, la qual los fonch rebuda en la present ciutat de València los dia, mes e any suprareferits: essent presents testimonis Francisco Sanchiz y Francisco Soriano, estudiants, de la ciutat de València vehins y habitadors.

Archivo del Corpus Christi. Notario Antoni Xavar. Protocolo 17359

\title{
XVII
}

Claustro general de medicina en el que se nombran jueces contadores.

\author{
Dicto die (25.11.1699).
}

In Dei nomine Amen. Noverint Universi. quod anno a Natyvitate domini millessimo sexcentesimo nonaguessimo nono, die vero intitulato vigessimoquinto, novembris. Salvador Moliner, Joan Batiste Gil, Basilio Delfí, Joan Batiste Ferris, Francisco Durbà, Martí Xalo, Pere Vicente Traver, Gaspar Felix Galindo, Joseph Antoni Gil, Bonaventura Viñau, Joseph Nebot, Tomas Guarch, Felip Carreres, Esteve Alegret, Tomas Longas, Macià Aznar, Joseph Bombaca, Batiste Frayle, Jaume Joan Sanz, Joseph Vicent Cases, Miquel Segobia, Vicent Bartolla, Andreu Vendrell, y Felip Jerejo, tots doctors en medicina, graduats de la present ciutat de València, junts y congregats en la Capella de Nostra Señora de la Sapiència, construida dins lo ambit de la Il.lustre Universitat de la dita present Ciutat hom per a semblants afers se solen y acostumen juntar y congregar, precehint convocació feta per Joseph Bertran, vedell de la dita Il.lustre Universitat, el qual mijançant jurament a nostre Senor Déu Jesuchrist y als Sants Quatre Evangelis en mà y poder del notari infraescrit, prestat, dix, y relació feu, ell haver convocat a tots los metges graduats de la dita facultat de Medicina de la present Ciutat per a el present dia, y lloch, els quals en nom del Il.lustre Claustre de Medicina y tot aquell representant (segons dixeren) de son bon grat, y certa ciència tots unànimes, y concordes, y ningú de aquells discrepant, nomenen en jutges contadors als dits Doctors Pere Vicent Traver y Gaspar Felix Galindo, de dita ciutat de València habitants., junts y acceptants a saber és, pera que en nom de dit Il.lustre Claustro puixen demanar contes al dit Doctor Joan Batiste Gil, com a depositari aue és de les propines de dit Il.lustre Claustro, aixl de la que ha adquirit y cobrat fins huy, com de Ies que en aban adquirirà y cobrarà de les que han estat, hl son y seràn de dit Il.lustre Claustro, y examinar aquells que lo dit Doctor Joan Batiste Gil presentara y fara ostensió, fent y fermant lo càrrech y descàrrech, contes, quantes vegades los pareixerà y sil pareixerà $\mathrm{el}$ puixen difinir en nom nostre y del dit Il.lustre Claustro y absoldrel, fent pactament, real quant personal, solemne y perpetuo de ulteriors aliquid non petendo, sive de non agendo, vel conveniendo, aixi en juhí, com fora dell, general y especialment imposanse silenci y 
callament perdurable circa predicta, del modo, forma y manera que a dits jutges contadors, lo pareixerà y ben vist los serà de tot ço y quant dit Il.lustre Claustro podrà demanar-li, rebre y cobrar a dit doctor Joan Batiste Gil en dit nom. Y sobre les dessús dites coses, y anexes a aquelles dependents, e independents, puixen fer los dits jutges contadors, en nom de dit Il.lustre Claustro qualsevols avinències, convencions; compossicions y pactes del modo, y manera que a dits jutges contadors los pareixerà. $Y$ a cerca dels dessús dit puixen en fermar, y fermen, qualsevols actes e instruments públichs, en poder de qualsevols notari ab les clàusules, modo y forma a dits jutges contadors ben vist $\mathrm{y}$ en semblants actes posar acostumades. Proquibus obligaverunt omnia et singula, bona et Iura dicti Il.lustris Claustri mobilia et inmobilia etc. Requibus etc. Actum Valentiae. etc.

Testes Gaudentius Alvarados, civis, et Antonius Miquel, scerici, Valentiae habitatores

Archivo del Reino de Valencia. Notario Juan Bautista Martínez de Gay. Protocolo 10195...-

XVIII

Claustro general de medicina en el que se da poder a sus electos para que paguen los gastos ocasionados por la elaboración de unas constituciones al abogado Tomás Leonardo Esteve.

Dicto die (25.11.1699)

In Dei Nomine Amen. Noverint Universi. quod anno a Natyvitate domini Millessimo Sexcentessimo nonaguessimo nono, die vero intitulato vigessimoquinto, mensis novembris. Salvador Moliner, Joan Batiste Gil, Basilio Derfí, Joan Batiste Ferris, Francisco Durbà, Martí Xalo, Pere Vicente Traver, Gaspar Felix Galindo, Joseph Antoni Gil, Bonaventura Viñau, Joseph Nebot, Tomas Guarch, Felip Carreres, Esteve Alegret, Tomas Longas, Macià Aznar, Joseph Bombaca; Batiste Frayle, Jaume Joan Sanz, Joseph Vicent Cases, Miquel Segobia, Vicent Bartolla, Andreu Vendrell, y Felip Jerejo, tots doctors en Medicina, graduats de la present ciutat de València, junts y congregats en la capella de Nostra Senora de la Sapiència, construhida dins lo àmbit de la Il.lustre Universitat de la dita present ciutat de València, hom per a semblants y altres afers se solen y acostumen juntar y congregar, precehint convocació feta per Joseph Bertran vedell de la dita Il.lustre Universitat, el qual mijançant jurament a nostre senor Déu Jesuchrist y als Sants Quatre Evangelis en mà y poder del notari infraescrit prestat, dix, y relació feu ell, haver convocat a tots los Metges graduats de la dita facultat de Medicina de la present Ciutat per a el present dia, y lloch, els quals en nom del Il.lustre Claustre de medicina, y tot aquell representant (segons dixeren) de son bon grat y certa ciència tots unànimes y concordes, ningú de aquells discrepants, deliberen que donen poder als elets que al presenta sont y per temps seran de dit Il.lustre Claustre de Medicina per a que puixen pagar a Tomas Leonart Esteve y. Casanova, doctor en Cascun drets, aquella cantitat que els pareixerà mès proporcionada y a rahó, conforme valer així lo paper de constitucions per a dit Il.lustre Claustro, que ha fet dit doctor Leonart de orde de dit Il.lustre Claustro, com tots y qualsevols treballs extra- 
ordinaris y juntes, que haja tengut aquell per conte del mateix Il.lustre Claustro donat los circa predicta, tot lo poder necesari y bastant, qual sia menester, y sia convenient, y tan general quant dit Il.lustre Claustro tinga y puixa tenir. Prequibus etc. obligaverunt omnia etc singula bona dicti Illustri Claustro mobili etc. Requibus etc. Actum Valentine etc. Testes Gaudencio Alvarado, civis, et Anthonio Miquel scerici, Val. hababitatores.

Archivo del Reino de Valencia. Notario Juan Bautista Martínez de Gay. Protocolo 10195.

XIX

Aprobación por los jueces contadores de las cuentas presentadas por el depositario del Claustro.

Dicto die (13.4.1700)

In Dei nomine. Amen. Noverint universi quod anno a nativitatis domini millessimo sexcentessimo, die vero intitulato decimo tertio aprilis. Pere Vicent Traver y Gaspar Felix Galindo, doctors en medicina, habitnnts de València, en nom de jutges contadors per a lo infraescrit, nomenats per lo Il.lustre Claustro de medicina com consta de nominació ab acte rebut per lo notari infraescrit, en vint y cinch de novembre propasat, tenint poder especial per a lo infraescrit, los quals pasaren a demanar contes a Joan Batiste Gil de Castelldases, doctor en medicina, habitant de València present depositari de les propines de dit Il.lustre Claustro, consta de la nominació ab acte rebut per Fulgencio Artich, notari, en vint y sis de juny de mil sis-cents noranta y tres, de totes les cantitats, que havia cobrat y entrat en son poder, propies de dit Il.lustre Claustro, precedides de qualsevols efectes, y de lo pagat per conte de dit Claustro, e ohit tot lo dessús dit per dit doctor Joan Batiste Gil de Casteldases, passa a donar conte de los desús dit, formant lo càrrech y descàrrech en la forma següent.

\section{Càrrech}

Primo: es fa càrrech lo dit doctor Joan Batiste Gil de catorce liures, dotse sous, y huit dines, moneda reals de València, per lo alcans contengut en los actes de difinició fet per los doctors Joan Batiste Ferris, Pere Vicent Traver, Gaspar Felix Galindo, Antoni Usson, y Felip Carreres, major part dels Elets de dit Il.lustre Claustro, en favor de dit doctor Joan Batiste Gil, rebut per dit Artich, en deu de setembre de mil siçents noranta y cinch.

Item: es faça càrrech de vint y dos liures del Priorato del doctor Salvador Moliner, contant desde dos de agost mil sis-cents noranta y sis, fins dos de agost de mil sis-cents noranta y set, incluit, per vint y dos graus, ço és, huit de doctor, y catorce de bachiller . 
Item: es fa càrrech del seu Priorato de dihuit liures dels anys mil siscents noranta set, en mil sis-cents noranta y huit; per dihuit graus, ço és, sis de doctors y dotse de bachiller.

Tots les quals partides del desus dit càrrech acumulades prenen suma universal de cinchquanta y quatre liures, dotse sous, y huit diners.

\section{Descàrrech}

Primo: dona en descàrrech lo dit doctor Joan Batiste Gil, sis liures que pagà al quondam Alexandre Arboreda, doctor en cascun dret, en la vila de Madrid, per lo coste de una carta de informe, segons albarà fet per aquell en dotse de agost mil sis-çents noranta y cinch..... Item: dona en descàrrech, una liura, set sous per consemblant pagades a Geroni Sadonis, en loch de vedell de la Il.lustre Universitat, per tres convocaçions generals del Il.lustre Claustro de medicina, fetes de orde del Il.lustre Rector, a instància del elets de dit Il.lustre Claustro, segons albarà firmat per aquell en cinch de agost mil siscents noranta huit.

Item: dona en descàrrech deu liures de àpoques pagades al doctor Alexandre Arboreda a compliment de totes les escriptures y treballs fets per aquell per conte y orde de dit Il.lustre Claustro, fins lo dia vint $\mathrm{y}$ tres de maig mil sis-cents noranta huit, segons àpoca fermada per aquell a favor del dit Il.lustre Claustro, rebuda per Joseph Arnal, notarí, en dit dia vint y tres de maig mil sisents noranta y huit.

6 liures Item: dona en descàrrech catorse liures, dotse sous, huit dines, entregades al doctor Joan Batiste Ferris per diferents gastos procesals segons albarà fermat per aquell en lo primer de febrer mil sisents noranta y sis.

Item: dona en descàrrech una liura, un sou, pagades a Antoni Xavar notari, per lo salari de nominació de elets per a nomenar dos advocats, per a que fesen estos unes constitucions, fet per dit Il.lustre Claustro, y rebut per dit Xavar, en tres de agost de mil sis-cents noranta y huit.

Item: dona en descàrrech dotse liures entregades al dit doctor Ferris, contengudes en dos albarans fermats per aquell, ço és, lo hu de huit liures, en vint y hu de agost mil sisents noranta y cinch, per a gastos procesals, y lo altre de cuatre liures, en lo primer de abril mil sisents noranta y nou per a gastos de una junta que es tingue de dos advocats per a tractar y discurrir sobre les fahedores per a el dit Il.lustre Claustro

Item: dona en descàrrech set liures, dotse sous, pagades a Pere Joan Ponts, per lo dret dels processos que es seguiren per dit Il.lustre Claustro, dels quals era escrivà lo dit Ponts, segons albarà fet per aquell en vint y tres de maig mil sis-cents noranta y nou..... 
Item: dona en descàrrech cinch liures pagades al dit Pere Joan Pont, a compliment de tots los drets procesals desús dits, segons albarà fet per aquell en quatre de juny propasat.

Item: dona en descàrrech dos liures, cinch sous pagades a Joseph Pasqual Flor, escrivent, per lo dret de escriure dos cópies de les desús dites constitucions, segons albarà fermat per aquell en vint $\mathrm{y}$ nou de mars propasat del corrent any

Item: dona en descàrrech, dos liures, dos sous pagades, ço és, al notari infraescrit, una liura un sou, per lo salari de la present. Y al dit Artich, una liura un sou, per lo salari de la difinició desús dita, rebuda per aquell, en deu de setembre de mil sis-cents noranta y cinch ....

Totes les quals partides del desús dit descàrrech prenen suma universal de sexanta dos liures, dos sous y huit diners per lo que queda crehedor lo dit doctor Joan Batiste Gil, contra lo dit Il.lustre Claustro, de set liures, deus sous de dita moneda. Per lo que los desús dits doctors Pere Vicent Traver, y Gaspar Felix Galindo, en dit nom, en virtut del poder desús dit absolven y difineixen al dit doctor Gil, present, acceptant, y als seus, de dits contes, confessant haver donat aquell bo; verdader, y legítim conte, y restant-li a deure lo dit Il.lustre Claustro, al dit doctor Gil, dites set liures, deu sous, reservant-li dret a aquell per a exigir, y cobrar aquelles de dit Il.lustre Claustro, y havent entregat totes les àpoques y cauteles en lo desús dit descàrrechs expressades, confesen tenir-les los desús dits, en son poder, fent pacte de ulterior aliquid non petendo, sive de non agendo, vel conveniendo. Imposant-se etiam dicto nomine circa predicta silenci y callament perdurable a dit Il.lustre Claustro, salvo semper quocumque errore recti calculi etc. et quia etc. Renuntiamus etc. Proquibus et omnia et singula bona, et jura dicti Claustri mobilia etc. Actum Valentiae etc.

Testes quo ad firma dicti doctores Gasparis Domingo Galindo, Joanes Baptista Ferris, Valentiae, et Philippus Carreres, medecinis doctores vicini mariveteris, extra Valentiae, habitatores. Quod vero ad firman dicti doctores Petri Vicentii Traver, qui Valentiae dicto die supra firmant fuerint et sunt testes Juseph Pujades, agricultor, horts de Rusafa, et Mathias Fenollosa, Valentiae habitatores.

Archivo del Reino de Valencia. Notario Juan Bautista Martinez de Gay. Protocolo 10196.

\section{$\mathbf{X X}$}

Claustro general de medicina en el que se nombran sus electos.

Die XIIII decembris anno a nativitnte domini MDCCIII (14.12.1703)

Anno a nativitate domini millessimo septingentessimo tertio. Die vero intitulato decimo quarto decembris. Juan Batiste Gil de Castelldases, Juan Batiste Caudí, Macià Domingo, Christofol Bayle; Juan Batiste Ferrís, Martí Xalo, Gaspar Gelix Galindo, Juseph Antoni Gil, Thomas Ballester, Bonaventura Vinau, Thomas Micó, Thomas Guarch, Salvador Perez, Feliph Carreres, Thomas Longas, Francisco Lorens, Basilio Cordella, Juseph Bertran,

Asclepio-Vol. XLV-1-1993 
Juan Batiste Frayle, Thomas Machauver, Jaume Sans, Juseph Casses, Miquel Segobia, Vicent Bartolla, Andreu Vendrell, Macià Morales, Juseph Balaguer, Prancisco Gilabert, Vitorino Brissa, Prudencio Bejarril, Juseph Gosalves, Francisco Garcia y Jacinto Catala, tots doctors en medicina de la present ciutat de València, en presència y asistència del Il.lustre don Manuel Mercader, prebere, doctor en Sagrada Theologia, Cànons y Lleys, Arcediano de Alzira, Rector de la Il.lustre Universitat de València, ajuntats y congregats en la Capella de Nostra Senora de la Sapiència, de dita Il.lustre Universitat, entre res 11 y 12 ores ans mig jorn, hon per a semblants y altres afers se solen y acostumen juntar y congregar precehint convocació feta per Juseph Bertran, vedell de dita Il.lustre Universitat, pressissa lo qual michansant jurament a Nostre Senor Déu Jesuchrist, y als sans quatre Evagelis, di aquell en mà y poder del notari infraescrit prestat, relació feu ell haver convocat a tots los desús dits y demés doctors, en medicina habitadors en la present ciutat, per a el present dia, hora y puesto, y essent així, tots junts afermant ésser la major part dels doctors en medicina habitant en la present ciutat y com a tals representant lo Il.lustre Claustro de medecina, y en nom de aquell tots unànimes y concordes y ningú discrepant de son bon grat y certa sciència per lo thenor de la present, per los respectes assí ben vists, instem de Elets de dit Il.lustre Claustro de medecina a Juan Battiste Gil de Casteldases; Juan Battiste Ferrís, Gaspar Felix Galindo, Juan Battiste Caudí; Felip Carreres, Martines Xalo, Juseph Nebot, y Juseph Bonbacar, doctors en medecina, quedant aquells ab tots los honors que et deu y requerixen y de nou en lo millor modo que podem nomenen en Elets de dit Illustre Claustro de medecina a Juan Batiste Gil de Castelldases, Juan Batiste Ferrís, Gaspar Felix Galindo, Juan Batiste Caudí, Felix Carreres, Martí Xaló y Juseph Antoni Gil, doctors en medecina, presents y acceptants, als quals donen y confereixen poder a tots junts eo a la major part de aquells per a reformar dit Il.lustre Claustro de medecina de la present ciutat y sa contribució, tantes y quantes vegades voldran y ben vist les serà en la mateixa conformitat y representació que acostuma la major part de tots los doctors graduats habitants en la present ciutat. Y que per a que puguen fer qualsevols actes y del.liberacions, y constitucions que els parega ésser necesaris, y convenients a dlt Il.lustre Claustro ab los pactes, condicions y penes y demés a aquells ben vistes per a conservació de los drets del mateix modo y forma que tot lo Il.lustre Claustro, eo la major part de aquell ho pot y acostuma fer y de tal modo y manera com si per tot lo Il.lustre Claustro fossen fetes. Y així mateix los donem poder y facultat a tots los desús dlts per a que aquells eo ab la major part de aquells puixen buscar y pendre qualsevols cantitats de diners que sien necessàries y menester y que aquelIs eo a la major part de aquells los parega y ben vist los sia, en una o més vegades per a qualsevol altra forma que el podran trobar, fent y firmant circa prodicta qualsevols actes neçessaris y opportuns en poder de qualsevols notaris ab totes les clàusules executories y guarentígies ab executòria llarga eo escomençant a peñores per pacte, com a deutes reals y fiscals de sa Magestat $a b$ jurament segons juraren en ànima sua respecte en mà y poder del notari infraescrit a Nos Déu etc., de no possar rahons ni exepcions algunes ab suvbenció y renunciació de son propi for, variació de juhy, traslació de drets y les clàusules de evicció, segons que valen ser tenguda en nom de dit Il.lustre Claustro, y de aquells de evicció llarga, expressa y paccionada etc. Y en cas de pendre, qualsevol fira eo fires despachant lletres a Medina del Campo y a hon convinga, y a qualsevols casses de fira cambiant y recambiant tantes quantes vegades voldran, fins tant estiguen dits canvis extints y pagats, ab tot los interesos, fermant qualsevols actes y cartes de indemnitat en favor de qualsevols notaris, escrites ab totes les clàusules en semblants actes possar acostumades, les quals volen tenir en lo present 
acte per repetides y expresades de verbo ad verbum, y per a que tot lo desús dit ab obligació de béns de dit Claustro y demés clàusules opportunes y necessàries, y en semblants actes possar acostumades segons lo estil y pràctica del notari o notaris rebedors de dits contractes y si opportucrit ad cautellam puixen renunciar en lo cas que convinga als benifets de cedir y dividir les actions noves y velles, constitucions y al fur de València, y a la epístola del divo Adrià, y a qualsevols altres que sia necessari, y que es trobe introduhit en favor de dit Claustro, les quals clàusules etiam volen tenir asi per expressades de verbo ad verbum. Y així mateix los donen poder a dits elets, eo a la major part de aquellos per cobrar dites y altres qualsevols cantitats, que a dit Il.lustre Claustro deguen y deuran qualsevols persones, colegis y universitats per qualsevol causa y rahó. Y de lo que cobraran puixen firmar y fermen qualsevols àpoques, cautelles y albarans en poder de qualsevol notari ab totes les clàusules necessàries y opportunes en semblants actes possar acostumades y així mateix per a que puixen escriure, y fer qualsevols representacions a sa Magestat (que Déu guarde) y aqui ben vist los serà, donant, donant-los circa prodicta tot lo dessús dit com lo demés que dit Il.lustre Claustro present y fer podria. Y tal qual lo té dit Il.lustre per a decidir, determinar, del.liberar, y posar en execució totes les cosses que ben vist los serà a aquells eo a la major part de aquells, ço és, als dits elets per a major conveniència, bon govern, lluiment y conservació dels drets de dita facultat. Y per a que puixen possar dits elets i la major part de aquells ab lo dit Il.lustre Rector qualsevol género de imposicions eo derrames de les cantitas que els pareixerà, per escala entre tots los doctors graduats de medecina y bachillers de la present ciutat y Regne, en lo modo que els pareixerà, fent decretar qualsevols actes que circa predicta per a rebre la clàusula general; de tal modo que volen y per lo desús dit poder algú no els falte ni se entenga poder-los faltar en manera alguna, ans be els donen a dits elets, eo a la major part de aquells, tan complit y general que lo dit Il.lustre Claustro fer, valer y tenir tot lo que per dits elets eo major part de aquells serà fet; tractat y procurat y no venir en temps algú contra lo fet y dispost per aquells ans be, desde ara, notifican y conforman de la mateixa manera, modo y forma que si per tot lo dit Il.lustre Claustro fou fet y del.liberat. Dequibus etc. Actum in dicta Illustris Universitatis. Proquibus etc.

Testes Michael Hyeronimeii Huyo, generosus, et Vicentius Alipus scerici gestor, Valentiae habitatores.

Archivo del Reino de Valencia. Notario Juan Bautista Martínez de Gay. Serie Gobemación, expediente 2788 , mano $10 a$, fol. 18

\section{XXI}

Deliberación de los electos de medicina en la que se aprueba la imposición de una derrama entre los doctores de Valencia, y la cuantía que deben pagar por cada uno de ellos.

Die V aprilis anno a nativitate domini MDCCIIII (5.4.1704)

In Dei nomine. Amen. Univerint universi quod anno a nativitate domini millessimo septingentessimo quarto die vero intitulato quinto aprilis. En lo aposento del Il.lustre se- 
nor Rector de la Il.lustre Universitat de València. Junts y congregats lo Il.lustre señor don Miquel Mercader, prebere, doctor en Sagrada Theologia, Rector de dita Il.lustre Universitat, Juan Batiste Caudí, Juan Batiste Ferrís, Martí Xalo y Gaspar Felix Galindo, doctors en medecina. Presehint convocació feta per Juseph Bertran, vedell de dita Il.lustre Universitat, el qual feu relació en mà y poder del notari infraescrit, medio juramento ad dominum deum etc., ell haver convocat a tots los elets de dit Il.lustre Claustro de mededina per a el present dia y loch, als quals en virtut del poder-que tenen de dit Il.lustre Claustro del.liberen que es pose, segons que ab tot effecte possasen y possen derrama en les persones y en la forma seguent.

\begin{tabular}{|c|c|}
\hline & 31. \\
\hline . Juan Batiste Gil ................................ & 31. \\
\hline Dr. Miquel Noguera & 31. \\
\hline 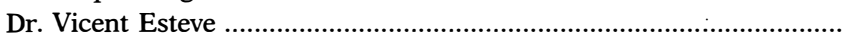 & 31. \\
\hline Dr. Basilio Delfí... & 31. \\
\hline Dr. Pere Miquel Lopes . & 21. \\
\hline 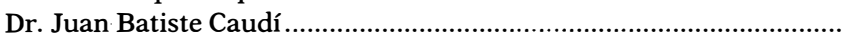 & $2 \mathrm{l}$. \\
\hline 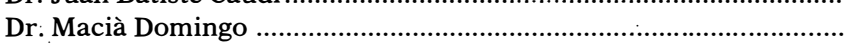 & 21. \\
\hline Dr. Juan Batiste Ferrís & 21. \\
\hline Dr. Esteve Falcó & 11. \\
\hline Dr. Francisco Duita & 21. \\
\hline 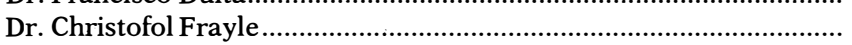 & 31. \\
\hline Dr. Martí Xalo & 31. \\
\hline Dr. Juseph Navarro .................................. & 31. \\
\hline 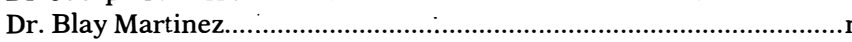 & xercita. \\
\hline 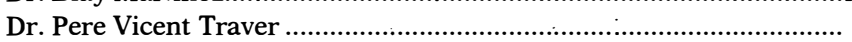 & 31. \\
\hline 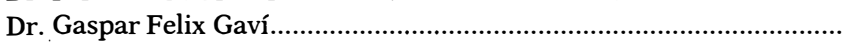 & 21. \\
\hline Dr. Thomas Micó .................. & 11. \\
\hline 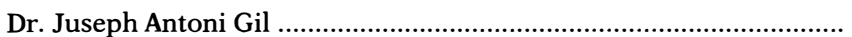 & 31. \\
\hline Dr. Raymundo Ronixa & xercita. \\
\hline 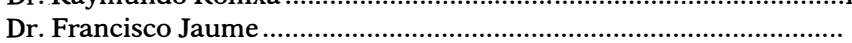 & 21. \\
\hline 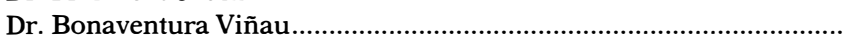 & 11. \\
\hline 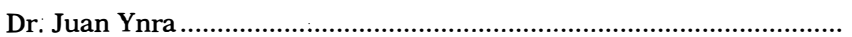 & $2 \mathrm{l}$. \\
\hline Dr. Juseph Nebot & 31. \\
\hline 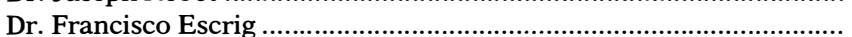 & 21. \\
\hline Dr. Salvador Perez & 21. \\
\hline 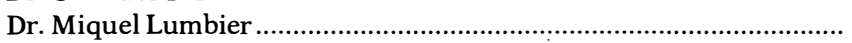 & 31. \\
\hline 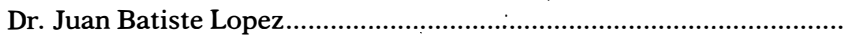 & 31. \\
\hline Dr. Thomas Guarch & $2 \mathrm{l}:$ \\
\hline 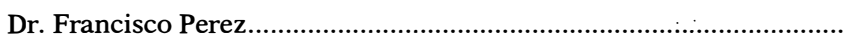 & 21. \\
\hline Dr. Juseph Cautí & 21. \\
\hline Dr. Basilio Costella ................. & $2 \mathrm{l}$. \\
\hline 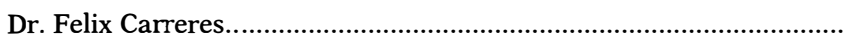 & 21. \\
\hline Dr. Esteve Argret. & 31. \\
\hline Dr. Pere Joan Planes & 31. \\
\hline r. Domingo Martinez................................... & 31. \\
\hline
\end{tabular}




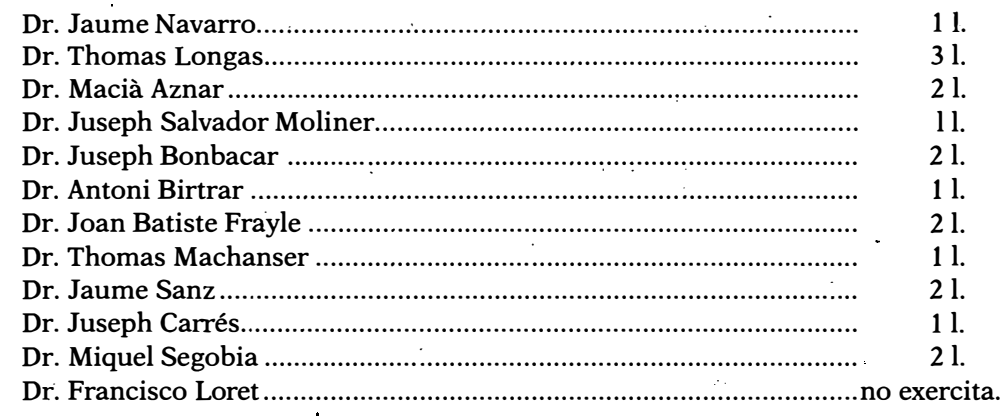

Archivo del Reino de Valencia. Notario Juan Bautista Martínez de Gay. Serie Gobernación, expediente $2788,10 .{ }^{a}$ mano, fol. 18.

\section{NOTAS}

(1) Las investigaciones sobre la Universidad de Valencia han proliferado durante los últimos años. Hacer una relación de todas ellas sería una tarea excesiva para el objeto de este trabajo, por ello únicamente citaré aquellas obras más extensas que han tratado la historia de la Universidad de Valencia durante la época moderna. Entre los trabajos ya clásicos no debe olvidarse a F. ORTI Y Figuerola (1730), Memorias históricas de la fundación y progresos de la insigne Universidad de Valencia, Madrid; J. TEIXIDOR Y TRILlES (1976), O. P., Estudios de Valencia (Historia de la Universidad hasta 1616). Edición, introducción, notas e índices por L: Robles, Valencia; M. Velasco y SANTos (1868), Reseña histórica de la Universidad de Valencia. Sus origenes y fundación, sus progresos y vicisitudes. Influjo que ha ejercido en el movimiento general científico y literario de España hasta el año 1845, Valencia y F. Vilanova y Pizcueta (1903), Historia de la Universidad Literaria de Valencia, Valencia. Estudios actuales de obligada referencia son los de M. BaLdó (1986), La Universitat de Valencia, Valencia; A. Felipo ORTs (1991), La Universidad de Valencia durante el siglo XVII (1671-1707), Valencia y (1992) La Universidad de Valencia durante el siglo XVI (1499-1611), Valencia; S. ALBIÑANA HUERTA (1988), Universidad e Ilustración. Valencia en la época de Carlos III, Valencia; M. Peset y M. ${ }^{2}$ Fernanda Mancebo, La Universidad de Valencia, en Instituto Juan Gil Albert, Alicante (en prensa).

(2) Para un estudio de la medicina y su significado social y científico pueden consultarse los trabajos de J. M. LÓPEZ PIÑERo (1969): La introducción de la ciencia moderna en España, Barcelona; "Valencia y la medicina del Renacimiento y del Barroco», en III Congreso Nacional de Historia de la Medicina, Valencia, vol. II, pp. 95-108; (1973), Medicina, Historia, Sociedad, Barcelona; (1976) Medicina moderna y sociedad española, siglos XVI- 
XIX, Valencia; (1979), Ciencia y técnica en la sociedad española de los siglos:XVI y XVII, Barcelona ; (1979) La Facultad de Medicina de la Universidad de Valencia. Aproximación a su historia, Valencia, entre otros.

(3) Los datos para el siglo XVI han sido tomados de J. Gallego Salvadores, «La creación pontificia y real", Universidades valencianas, pp. 43 y 45; los del XVII de.A. FeLIPO, Felipe IV y el Reino de Valencia, Valencia, p. 740 y M. y J.L. PĖSET, M. ${ }^{a}$ F. MANCEBo, «La población universitaria de Valenciai, en Estudis d'historia contemporània del País Valencià, núm 1, Valencia 1979, vide cuadros adjuntos.

(4) Constitucions del Estudi General de València fetes en onze de maig any mil siscents y onze, Valencia 1655, cap. VIII. Esta organización no sufrió modificaciones en las Constituciones de 1651 y 1674, ni en las ordenanzas de 1654 y 1663. Reglas que se mantendrían durante los comienzos del siglo XVIII y hasta las Constituciones de 1733 como prueba una descripción de las cátedras de medicina y sus salarios de 1721 que se encuentra en Bulas, Constituciones y documentos de la Universidad de Valencia (1707-1724).

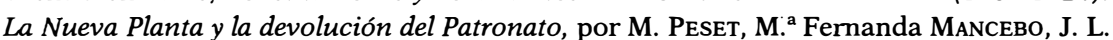
PeSeT y A. M. ${ }^{a}$ Aguado (1977), Valencia.

(5) Las noticias de claustros particulares de cada facultad eran esporádicas. Así, S. García Martínez (1968), en Els fonaments del País Valencià modern, Valencia, p. 130, afirmaba que: Altres organismes col.legiats - de la Universidad-eren el Claustre General de catedràtichs $i$ doctors - de caracter consultiu i escassa efectivitat-i el Claustre de cada Facultat, que s'ocupaba de problemes especifics d'aquestes.

(6) M. E. MuÑoz-(1751), Recopilación de las leyes, pragmáticas reales, decretos, y acuerdos del Real Proto-medicato. Valencia, p. 376. En él, se dice que el Claustro de medicina posee «la costumbre de tener y formar Claustro distinto, y separado de todas las otras Facultades; de suerte que si se ofrecia aver de tratar algún negocio perteneciente a esta Facultad; su estado, aumento, y honor, el Rector de la Universidad mandava al vedel, convocar a los Doctores de Medicina, que se congregavan en la Capilla de ella, con assistencia, y presidencia del Rector o Vice-Rector; y assi iuntos, propuesto, y deliberado el assunto de la convocación, se recibía Escritura pública del punto deliberadon. Con facultad para «hacer Ordenanzas, y Estatutos pertenecientes al estado, aumento, conservación y honorificiencia de la misma Facultad". También hacía referencia a estos claustros ORTI (p. 29). (Las restantes referencias a ORTf́ corresponden a esta página).

(7) Archivo del Reino de Valencia (A.R.V.). Sentencias. 2241. En el mismo año, el libro de priorato de medicina recogía una anotación del tenor siguiente: «En este año de 1677 en 17 de noviembre dio sentencia en favor del Claustro de medicina contra el Patrimonio Real, de ser cuerpo separado de los demás claustros, y tener toda fuerça de derecho con la asistencia del Rector y de la maior parte de los de la juntan-Archivo de la Universidad de Valencia. Libro de Priorato, sig. 87-. Y Muñoz en su Recopilación..., p. 377 afirmaba que con en esta sentencia se admitió que el Claustro había probado «la possessión" - de dicho privilegio- "de más de treinta años», M. E. MuÑoz, Recopilación..., p. 377. Noticia de esta sentencia también se aporta en el documento número dos (II).

(8) M. ${ }^{a}$ Luz López Terrada y J. Pardo Tomás, «El Protomedico y sobrevisitador real a la Valencia del segle XVI", Afers, 5/6 1687, pp. 211-222. 
(9) Pueden verse los que se encuentran en Archivo del Corpus Christi (A.C.C.), Protocolos, notario Ignaci Avellaneda, protocolo 5096, en las fechas de 30 y 31 de enero, 1 de febrero, 16 de noviembre, entre otras.

(10) No he transcrito las designaciones de síndico y procurador porque no se diferencian de las demás escrituras notariales que recogen estos nombramientos. Para los de síndico: A.C.C., Protocolos, 14967, el 13 de junio de 1683; A.R.V., Protocolos, 10196, el 26 de octubre de 1700, entre otros; para los de procurador: A.C.C. Protocolos, 5079, de fecha 5 de febrero de 1694.

(11) L.S. Granjel (1974), El ejercicio médico; Salamanca.

(12) J. PARDo TOMÁs (1988), «El personal sanitario», Historia de la medicina valenciana, Valencia, p. 153.

(13) Sebastián García Martínez (1969), "Un intento de seguro médico en Valencia (1684)", en Actas del Congreso Nacional dc Historia de la Medicina, 3 vols. Valencia, pp. 187-191. El autor nos proporciona un valioso documento en el que se pone de manifiesto la oposición de gremios y congregaciones a la resolución aprobada en este claustro pero, al desconocer su contenido, no pudo reconocer que se trataba de una práctica habitual anterior.

(14) A.R.V. Gobernación. EXP. 2788, 10.a mano, fol. 18.

(15) Para una mayor información sobre este punto puede consultarse A. FeLIPo, La Universidad..., pp. 250-255.

(16) Este importante memorial ya fue editado por V. PESET (1961), en Asclepio XIII, pp. 143 a 155 , y se encuentra igualmente transcrito en M. PESET y otros en Bulas..., p. 262, texto 212. El capítulo XI, apdo. 8 de las Constituciones de 1733 decía: «Otrosí, ordenamos que mientras no se imprimen de nuevo los libros por donde regularmente se estudia la Medicina, con la addición de las noticias que parecieren necessarias, o otros nuevos, en lo que se está tratando, deva cada Cathedrático en su explicación y tratados, instruir a los Estudiantes en la noticia de lo que modernamente se ha descubierto en la Medicina; bien que procurando en primer lugar establecer los principios y fundamentos sobre que estriva la legítima inteligencia de esta Facultad".

(17) Archivo de la Universidad de Valencia. sig. 87, Liber prioratus claustri medicinae, fol. $56 \mathrm{~V} .^{\circ}$, y en M. PESET y otros, Bulas..., p. 107.

(18) M. PESET y otros, Bulas..., pp. 133 y ss. textos núm. 108 y 109.

(19) A.R.V. Real Acuerdo, lib. 30, año 1735, fol. 532.

(20) Furs, capitols, provisions e acte de Cort..., Monzón 1626, Valencia, 1635, cap. XI de los actos de corte del brazo real, fol. 48: Item senyor, com sia molt necessari al be públich, que los qui voldran exercitar la art de medicina, tinguen la doctrina y suficiència necessaria, y la experiència ha mostrat no tenirla alguns que han volgut exercitar dita art, jatsia hajen mostrat tenir alguns graus de algunes universitats. Pero ço, suplica a V. M. lo dit estament real, sia servit de ordenar y manar per acte de la present cort, que ningú puixa exercitar la art de medicina en la ciutat de València, ni en part alguna del Regne, que no sia graduat en la universitat, y estudi general de dita Ciutat, o no sia incorporat alli, en cas que sia graduat en altra part, o no sia per lo menys examinat en particular per los examinadors de la facultat de medicina que estan nomenats per als graus de dita facultat ques donen en

Asclepio-Vol. XLV-1-1993 
dita universitat, y estudi general, y tinga aprobació de aquells, ab la qual sia donat per habil per a curar. Plau a Sa Magestat, sens periuhí de qualsevol privilegis que tinguen los doctors en medicina graduats en la Universitat de València.

(21) Véase la alegación jurídica presentada en el pleito entre la ciudad y los examinadores reales de Valencia con la Universidad de Gandía, aportado por M. PESET y otros en Bulas..., p. 145 y ss.

(22) A R.V. Real Acuerdo, lib. 31, año 1736, fol. 299. Muñoz también recoge enteramente esta disposición -M. E. MuÑoz, Recopilación..., fol. 387 y ss.-.

(23) A.R.V. Real Acuerdo, lib. 31, fol. 305. 